\title{
WestVirginiaUniversity
}

THE RESEARCH REPOSITORY @ WVU

Graduate Theses, Dissertations, and Problem Reports

2009

\section{Predicting the performance of horizontal wells in unconventional gas reservoirs}

\author{
Dylan Todd Drinkard \\ West Virginia University
}

Follow this and additional works at: https://researchrepository.wvu.edu/etd

\section{Recommended Citation}

Drinkard, Dylan Todd, "Predicting the performance of horizontal wells in unconventional gas reservoirs" (2009). Graduate Theses, Dissertations, and Problem Reports. 2038.

https://researchrepository.wvu.edu/etd/2038

This Thesis is protected by copyright and/or related rights. It has been brought to you by the The Research Repository @ WVU with permission from the rights-holder(s). You are free to use this Thesis in any way that is permitted by the copyright and related rights legislation that applies to your use. For other uses you must obtain permission from the rights-holder(s) directly, unless additional rights are indicated by a Creative Commons license in the record and/ or on the work itself. This Thesis has been accepted for inclusion in WVU Graduate Theses, Dissertations, and Problem Reports collection by an authorized administrator of The Research Repository @ WVU. For more information, please contact researchrepository@mail.wvu.edu. 
Predicting the Performance of Horizontal Wells in Unconventional Gas Reservoirs

Dylan Todd Drinkard

Thesis submitted to the
College of Engineering and Mineral Resources
at West Virginia University
In partial fulfillment of the requirements

For the degree of

Master of Science

In

Petroleum and Natural Gas Engineering

Kashy Aminian, Ph.D. Chair

Ilkin Bilgesu, Ph.D

Samuel Ameri, M.S

Department of Petroleum and Natural Gas Engineering

Morgantown, West Virginia

2009

Keywords: Unconventional Reservoirs, Coalbed Methane, Horizontal Wells, Type Curves, Gas Production Prediction.

Copyright 2009 Dylan Todd Drinkard 


\begin{abstract}
Predicting the Performance of Horizontal Wells in Unconventional Gas Reservoirs
\end{abstract}

\title{
Dylan Todd Drinkard
}

Unconventional gas has become an increasingly important component of total U.S. domestic production for the past decade. Currently, only numerical models (simulators) can be used to predict production behavior in unconventional gas reservoirs. Numerical models are expensive and time consuming and the needed variables for evaluations are often unknown or only estimated.

This research has focused on developing a simple, quick, and reliable tool to predict gas production from horizontal wells in the unconventional gas reservoirs. This study presents a set of production type curves for coalbed methane (CBM) reservoirs. A reservoir model that incorporates the unique flow and storage characteristics of CBM reservoirs was used to generate production profile by varying reservoir parameters. The production profiles were then analyzed to develop two sets of unique type curves for horizontal CBM wells. These two sets of production type curves are for the two flow regimes associated with the horizontal wells namely linear flow early and elliptical flow late in the life of the well.

Porosity, Langmuir volume, drainage area size, well length were found not to impact type curves significantly. The ratio of well length to reservoir length was found to influence the type curves significantly. Langmuir pressure and horizontal permeability were found to have minor impact on the shape of the type curve. Drainage shape was assumed to be rectangle since it is the more effective drainage area for horizontal wells. The impact of drainage area shape was not investigated in this study. 


\section{Acknowledgements}

I would like to thank Dr. Kashy Aminian for being my advisor and helping me complete this project. His professionalism and knowledge of subject is superb. His help, professional assistance, and advice were greatly appreciated.

I would also like to thank the other members of my committee. Sam Ameri, Professor and Head of the Petroleum and Natural Gas Engineering Department, has helped me tremendously over the past two years. His support and continuous motivation was a wonderful asset. Dr. Ilkin Bilgesu, I thank you for your wisdom, communication skills as an educator, and most of all the support you have given me during my education at West Virginia University.

I would like to thank my Grandparents for all of their love and support throughout my entire life.

Lastly, I thank my parents, William and Marjorie Drinkard. Their unconditional love and support has taught me to understand that one can accomplish anything if he/she has the right mindset. I cannot thank you enough

Much love and respect to all. 


\section{TABLE OF CONTENTS}

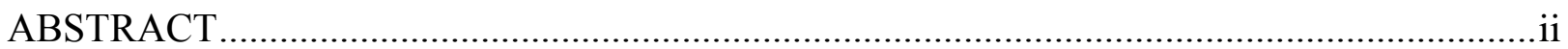

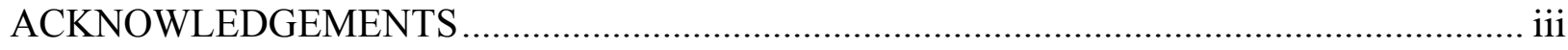

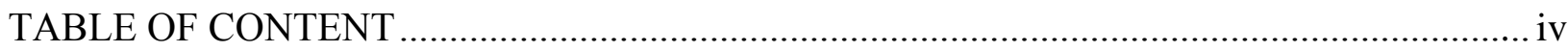

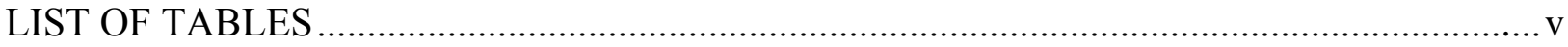

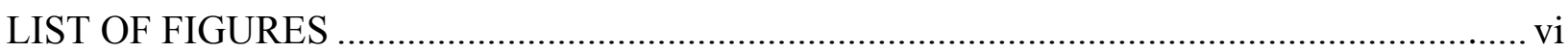

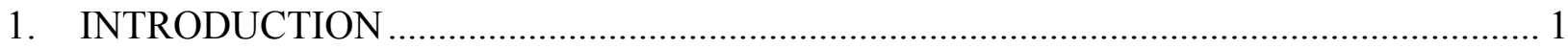

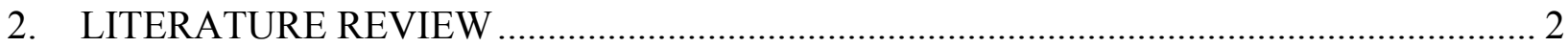

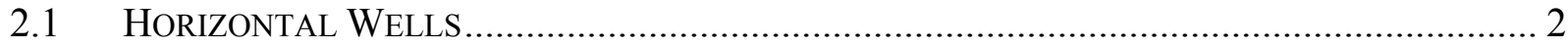

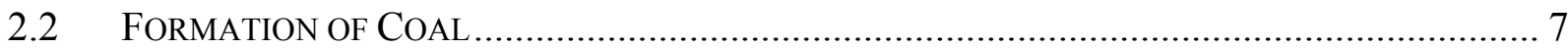

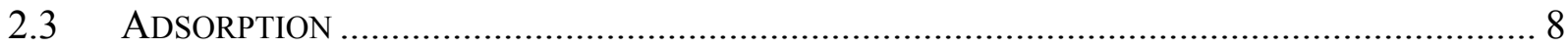

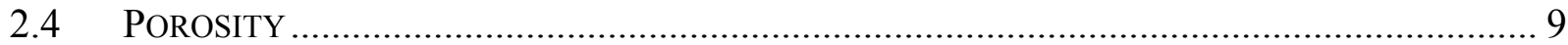

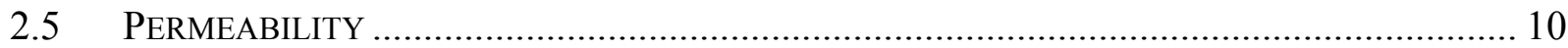

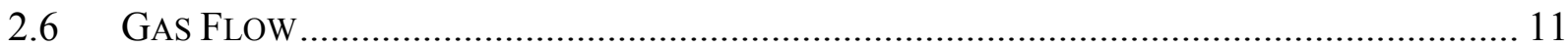

2.7 TyPe CURVES For CoAlBed METHANE …............................................................ 13

2.8 NUMERICAL MODELS AND ASSUMPTION............................................................ 15

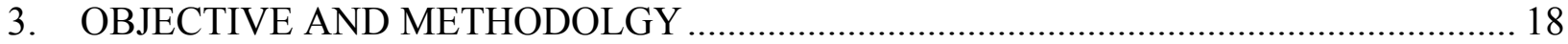

3.1 BASE MOdEL DEVELOPMENT AND ASSUMPTIONS.................................................. 18

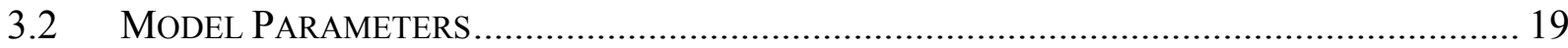

3.3 EVAluating DifFERENT Dimensionless Groups FOR TyPe CuRVE DEVElOPMENT ... 20

3.4 Methodology for ApPlication of Type Curve for Production Prediction....... 22

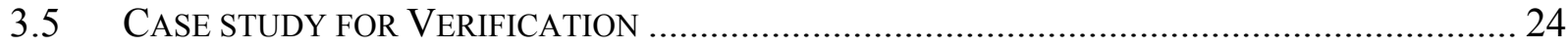

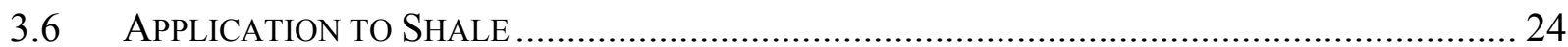

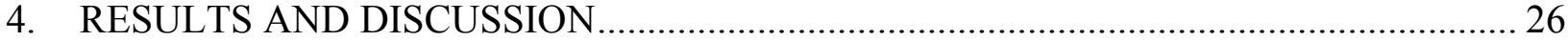

5. CONCLUSIONS AND RECOMMENDATIONS ....................................................... 37

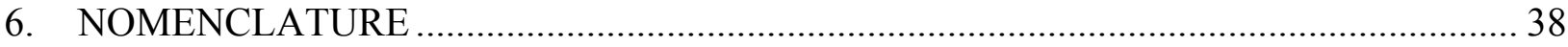

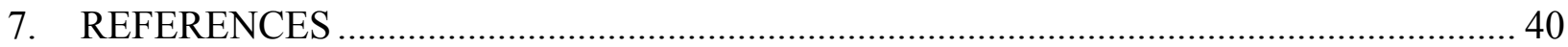




\section{List of Tables}

TABLE 1. SHAPE RELATED SKIN FACTORS FOR HORIZONTAL WELL ${ }^{18} \ldots . . . . . .4$

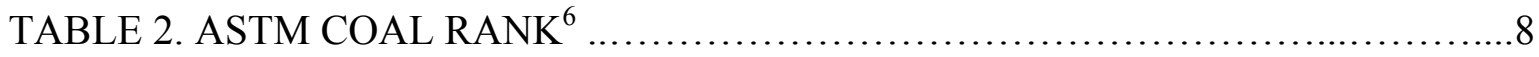

TABLE 3. VALUES AND RANGES OF PARAMETERS USED IN MODEL ............20

TABLE 4. INPUT PARAMETERS FOR BASE CASE MODEL $\ldots \ldots \ldots \ldots \ldots \ldots \ldots \ldots . . . \ldots 21$

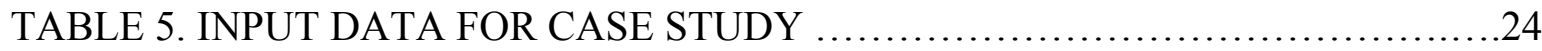




\section{List of Figures}

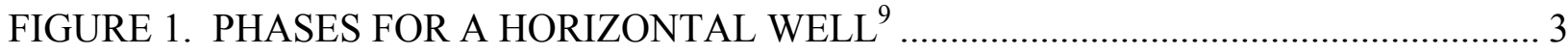

FIGURE 2. EFFECTS OF HORIZONTAL WELL PENETRATION ON TYPE CURVES. ...... 5

FIGURE 3. EFFECTS OF DRAINAGE AREA SHAPE ON TYPE CURVES. .......................... 5

FIGURE 4. TYPE CURVE FOR HORIZONTAL WELLS IN INFINITE RESERVOIRS ${ }^{16} \ldots . . .6$

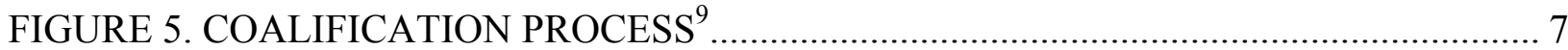

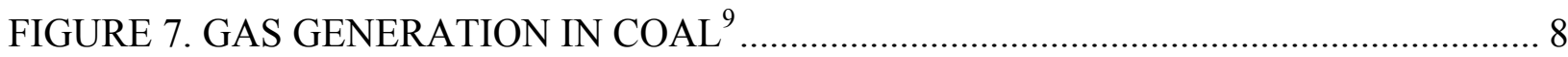

FIGURE 8. PRODUCTION DECLINE FOR VERTICAL WELL ............................................. 12

FIGURE 9. TYPE CURVE FOR VERTICAL CBM PRODUCTION .................................... 14

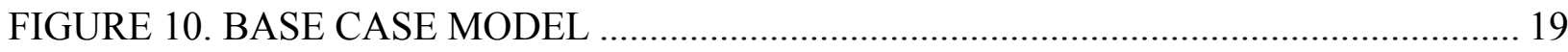

FIGURE 11. TYPE CURVE DEVELOPMENT FOR EARLY PRODUCTION …………......... 23

FIGURE 12. TYPE CURVE DEVELOPMENT FOR LATE PRODUCTION ………................. 23

FIGURE 13. COMPARISON OF CBM AND SHALE TEMPLATE MODEL ……................... 25

FIGURE 14. IMPACT OF THE POROSITY VARIATION ON THE TYPE CURVE FOR

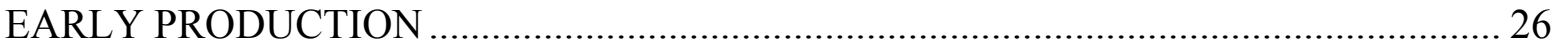

FIGURE 15. IMPACT OF THE POROSITY VARIATION ON THE TYPE CURVE FOR

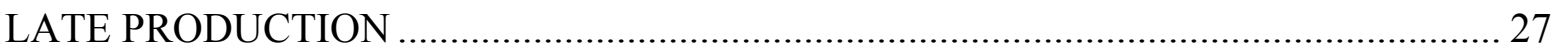

FIGURE 16. IMPACT OF DRAINAGE AREA WHEN COMPARING L/YE RATIO ............. 28

FIGURE 17. IMPACT OF DRAINAGE AREA ON THE TYPE CURVE WHEN

COMPARING L/YE $=0.25$ FOR LATE PRODUCTION .............................................. 29

FIGURE 18. IMPACT OF DRAINAGE AREA ON THE TYPE CURVE WHEN

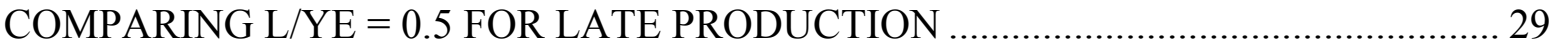

FIGURE 19. IMPACT OF DRAINAGE AREA ON THE TYPE CURVE WHEN

COMPARING L/YE $=0.75$ FOR LATE PRODUCTION ................................................ 30

FIGURE 20. IMPACT OF THE PERMEABILITY VARIATION ON THE TYPE CURVE

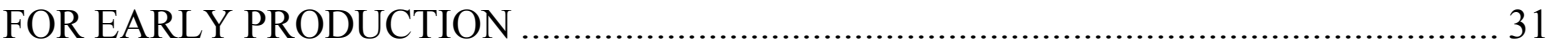

FIGURE 21. IMPACT OF THE PERMEABILITY VARIATION ON THE TYPE CURVE

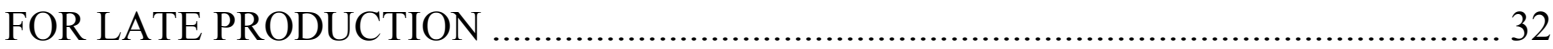

FIGURE 22. IMPACT OF LANGMUIR PRESSURE CHANGES ON TYPE CURVES

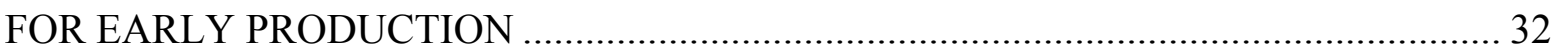

FIGURE 23. IMPACT OF LANGMUIR PRESSURE CHANGES ON TYPE CURVES

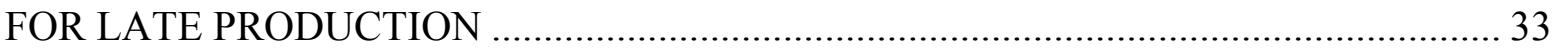

FIGURE 24. IMPACT OF LANGMUIR VOLUME CHANGES ON TYPE CURVES FOR

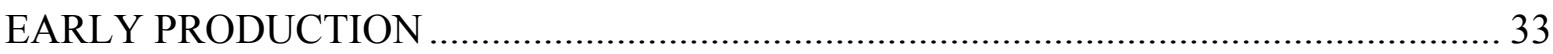

FIGURE 25. IMPACT OF LANGMUIR VOLUME CHANGES ON TYPE CURVES FOR

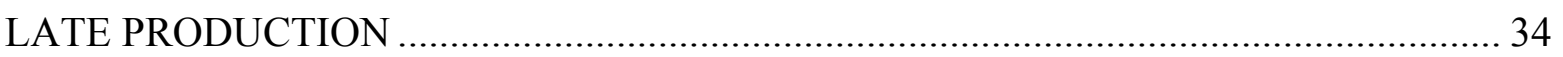

FIGURE 26. COMPARISON OF THE PREDICTED GAS PRODUCTION ……………......... 35

FIGURE 27. COMPARISON OF PREDICTED CUMULATIVE GAS PRODUCTION........... 36 


\section{INTRODUCTION}

Unconventional gas includes natural gas extraction from coalbeds, low-permeability sandstones, and shale formations. Unconventional gas reservoirs have become an increasingly important source of U.S. domestic production of the past decade. Over the next two decades, the role of unconventional gas in meeting the nation's energy needs is projected to increase by approximately $60 \%{ }^{1}$ Therefore, it is necessary to develop tools that make it possible for producers to exploit this important resource.

In horizontal coalbed methane wells, the principal benefit is that the borehole can be controlled with respect to the principal permeability directions of the coal seam. This improves production by using the natural fracture network which enhances the rate of water production and accelerates the gas production compared to a vertical well. While there is a significant potential in gas recovery in horizontally drilled wells verse vertically drilled wells, a technical and economical evaluation should be completed before deciding which technique is best suited for the reservoir.

There is no simple/easy to use methodology for predicting the production performance of the horizontal well in unconventional reservoirs. The conventional horizontal well decline curve methods cannot be used to predict production behavior due to the complex nature of unconventional reservoirs. Production from coalbed methane (CBM) reservoirs is controlled by the complex interaction of gas desorption from the coal matrix and two-phase flow of gas and water through the cleat system. The performance of CBM and shale reservoirs can best be predicted by numerical reservoir simulators that account for various mechanisms that control the gas production.

The use of reservoir simulators to evaluate CBM prospects at early stage of development is difficult, time consuming, and expensive due to lack of sufficient data. Type Curves provide a simple and yet reliable alternative to simulation. However, there are no type curves available for horizontal wells in CBM reservoirs. 


\section{LITERATURE REVIEW}

\subsection{Horizontal Wells}

The use of the directional (horizontal) wells is not a new idea but advances in technology have drastically changed its efficiency. The technology itself dates back to 1891, when the first patent was granted for equipment to be placed in a horizontal hole from a vertical well. ${ }^{14}$ A directional drilled well is defined as a well bore that intersects a potentially productive formation and does not exit the formation for the remaining footage drilled. This is completed by drilling a conventional vertical well and then at a determined "kick off" point (KOP) the well is deviated from the vertical so that the well bore enters the formation roughly parallel to the formation.

In horizontal coalbed methane reservoirs, the principal benefit is that the borehole can be controlled with respect to the principal permeability directions of the coal seam. The well is placed normal to the highest permeability which is perpendicular to the face cleats. This improves production by using the natural fracture network which enhances the rate of water production, and accelerates the gas production compared to a vertical well. While there is a signification potential in gas recovery in horizontally drilled wells verses vertically drilled wells, a technical and economical evaluation should be completed before deciding which technique is best suited for the reservoir.

Horizontal wells pose two special problems for the reservoir engineer. The first is the unavoidable large wellbore storage effect. Horizontal sections may extend for thousands of feet and cannot be isolated from transient. The second is the more complex nature of the transient. Once wellbore storage is stabilized, three regimes possibly replace the radial-flow regime of a conventional test.

First is radial flow in a vertical plane toward the well, indicated by a plateau on the derivative curve on a log-log plot, the regime is termed early-time pseudo-radial because permeability anisotropy actually causes an elliptical flow pattern. If the formation height is small, or if $\mathrm{k}_{\mathrm{v}} / \mathrm{k}_{\mathrm{H}}$ is small, this early radial flow may not be present. The second flow regime begins when the transient reaches the upper and lower boundaries of the producing zone and 
flow becomes linear toward the well within the horizontal plane. The derivative curve traces a line of a slope $1 / 2$. The third regime, late-time pseudo-radial flow, occurs as the transient moves so far from the well that flow becomes radial again, but this time in the horizontal plane. The derivative curve enters a second plateau.

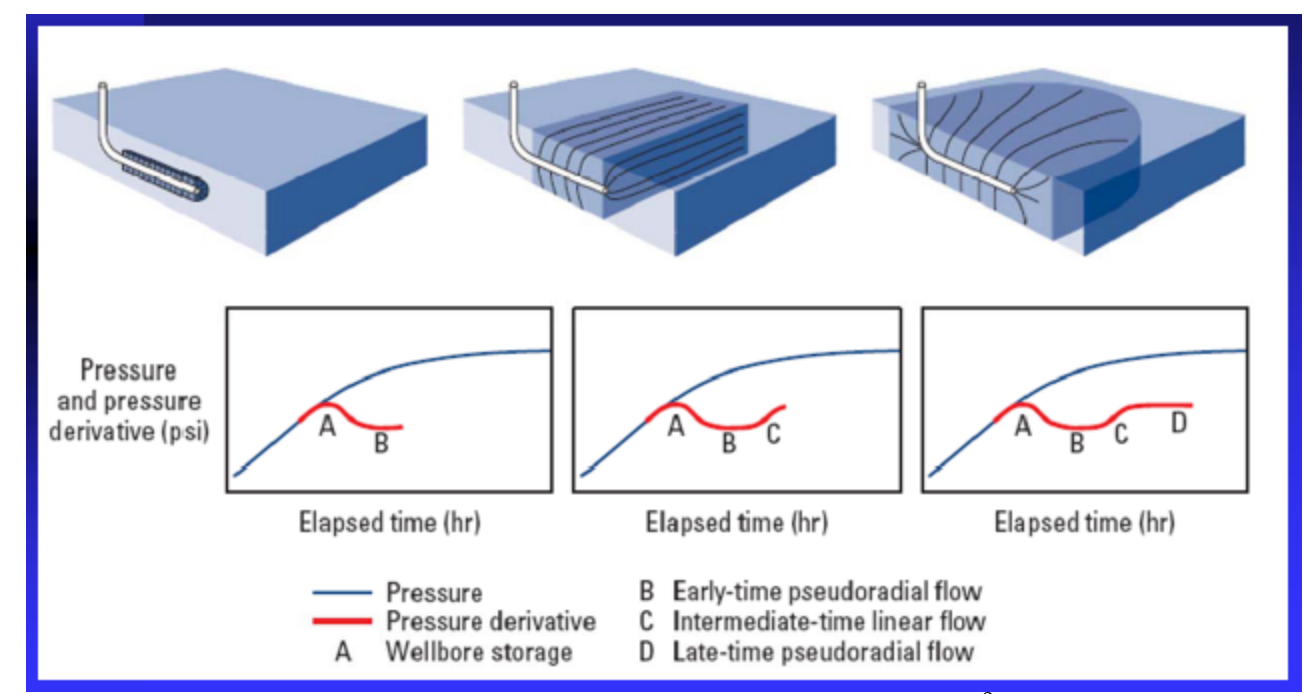

Figure 1. Phases for a Horizontal Well ${ }^{9}$

The pseudo-steady state equation for a horizontal well is given as: ${ }^{18}$

$$
\mathrm{q}=\frac{0.0007027 \mathrm{kh}\left(\overline{\mathrm{p}}^{2}-\mathrm{p}_{\mathrm{wf}}{ }^{2}\right)}{\mathrm{Tz \mu}\left[\ln \left(\frac{\mathrm{r}_{\mathrm{e}}}{\mathrm{r}_{\mathrm{w}}}\right)-0.738+\mathrm{s}+\mathrm{s}_{\mathrm{m}}+\mathrm{s}_{\mathrm{ca}}+\mathrm{c}^{\prime}+\mathrm{Dq}\right]}
$$

In Equation 2.1, $\mathrm{s}_{\mathrm{m}}$ represents mechanical skin factor due to drilling and completion relating to well damage. The skin factor, $\mathrm{s}$, is an arithmetic addition of skin factors due to partial well penetration, perforations, and fracture and acid stimulation which is shown if Equation 2.2. Dq represents near wellbore turbulence, $\mathrm{s}_{\mathrm{ca}}$ represents shape factor, and $\mathrm{c}^{\prime}$ represent the shape factor conversion constant.

$$
s=-\ln \left(\frac{L}{r_{w}}\right)
$$

For horizontal wells, in addition to the side boundaries of the areal drainage plane, the top and bottom reservoir boundaries also influence the well productivity. A horizontal well shape factor depends upon: 
1. Drainage area shape

2. Well penetration

3. Dimensionless well length

The shape-related skin factors for horizontal wells, $\mathrm{s}_{\mathrm{CA}, \mathrm{h}}$ are tabulated in Table 1.

Table 1. Shape Related Skin Factors for Horizontal Well ${ }^{18}$

\begin{tabular}{|c|c|c|c|c|c|}
\hline \multicolumn{6}{|c|}{ L/Ye } \\
\hline LD & $\mathbf{0 . 2}$ & $\mathbf{0 . 4}$ & $\mathbf{0 . 6}$ & $\mathbf{0 . 8}$ & $\mathbf{1}$ \\
\hline $\mathbf{X e} /$ Ye = 2 & & & & & \\
\hline 1 & 4.425 & 4.578 & 5.025 & 5.42 & 5.86 \\
\hline 2 & 2.84 & 3.01 & 3.13 & 3.26 & 3.46 \\
\hline 3 & 2.38 & 2.45 & 2.61 & 2.73 & 2.94 \\
\hline 5 & 1.982 & 2.02 & 2.15 & 2.31 & 2.545 \\
\hline 10 & 1.74 & 1.763 & 1.85 & 1.983 & 2.198 \\
\hline 20 & 1.635 & 1.651 & 1.72 & 1.839 & 2.04 \\
\hline 50 & 1.584 & 1.596 & 1.65 & 1.762 & 1.959 \\
\hline 100 & 1.572 & 1.582 & 1.632 & 1.74 & 1.935 \\
\hline
\end{tabular}

There has been type curves developed for predicting horizontal well production. The dimensionless groups investigated were developed for predicting horizontal well production for an unconventional finite and infinite reservoir.

$$
\begin{gathered}
t_{D A}=\left(\frac{0.001055 k_{H}}{\varphi c_{t} \mu A}\right) t \ldots \\
G_{p D \text { area }}=\left(\frac{36 T}{h \varphi c_{t} A P_{p}}\right) G_{p}
\end{gathered}
$$

In equation 2.3 and 2.4, the dimensionless cumulative production and time was base on the drainage area. Figure 2 illustrates the effect of horizontal well penetration on long term production behavior of the horizontal wells. Figure 3 compares the performance of a horizontal well in a square drainage area versus a rectangular drainage area when the direction of the well coincides with the longer side of the rectangle. The drainage area for a horizontal well approaches an elliptical shape. As a result, the performance of the horizontal well in a drainage area is improved over a square drainage area ${ }^{16}$. The horizontal well penetration and the geometry of the drainage area influence the type curves. 


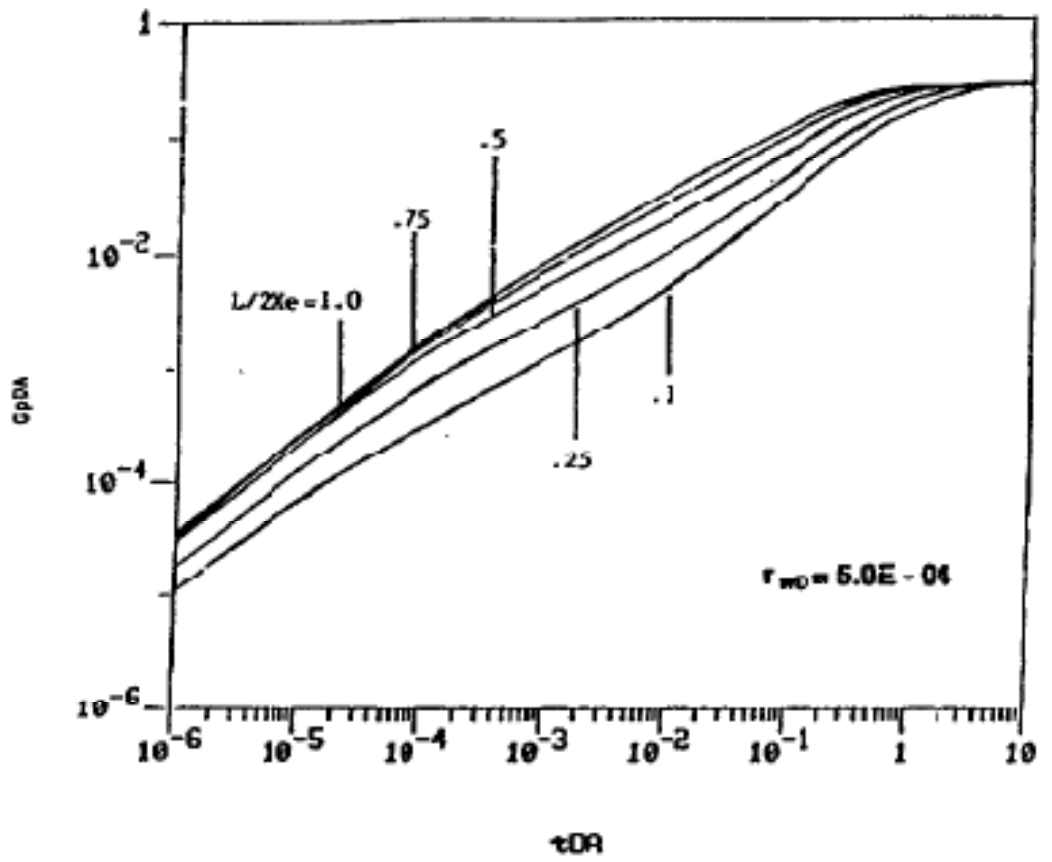

Figure 2. Effects of Horizontal Well Penetration on Type Curves.

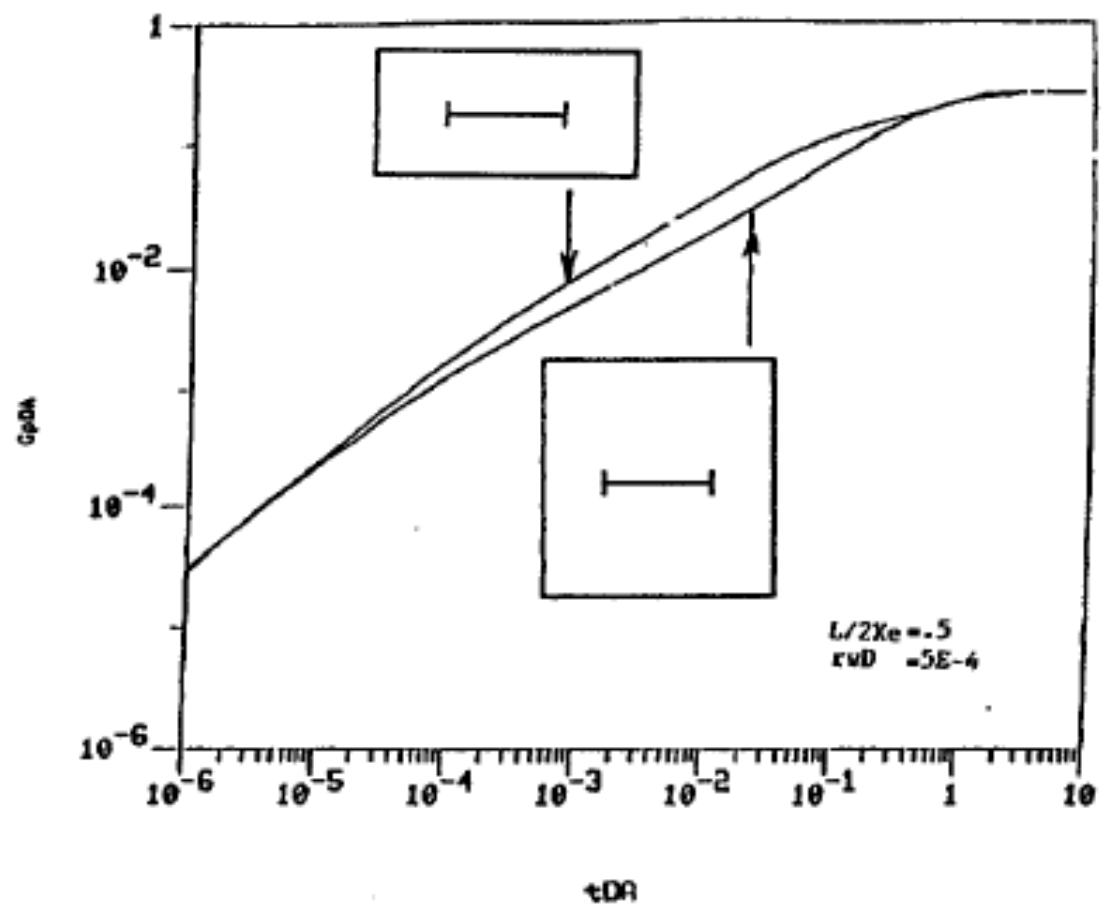

Figure 3. Effects of Drainage Area Shape on Type Curves. 
In equation 2.5 and 2.6, the dimensionless cumulative production and time was base on the wells lateral length.

$$
\begin{gathered}
t_{D L}=\left(\frac{0.001055 k_{H}}{\varphi c_{t} \mu L^{2}}\right) t \ldots \ldots \\
G_{p D \text { length }}=\left(\frac{36 T}{h \varphi c_{t} L^{2} P_{p}}\right) G_{p}
\end{gathered}
$$

Horizontal production type curves can be effectively grouped by two dimensionless terms, the dimensionless wellbore radius $\left(\mathrm{r}_{\mathrm{wD}}\right)$ and the dimensionless well length $\left(\mathrm{L}_{\mathrm{D}}\right)$. The definitions of these two dimensionless terms are given below: ${ }^{16}$

$$
\begin{aligned}
& L_{D}=\frac{L}{2 h}\left(\frac{k_{v}}{k_{H}}\right) \\
& r_{w D}=\frac{2 r_{w}}{L} \ldots
\end{aligned}
$$

Figure 4 illustrates the type curve for an infinite reservoir. The type curve is influenced by the dimensionless well length.

When a horizontal well is sufficiently long, $L_{D}>10$, the influence of the top and bottom boundaries becomes small and performance of a horizontal well approaches that of a fully penetrating infinite-conductivity fracture.

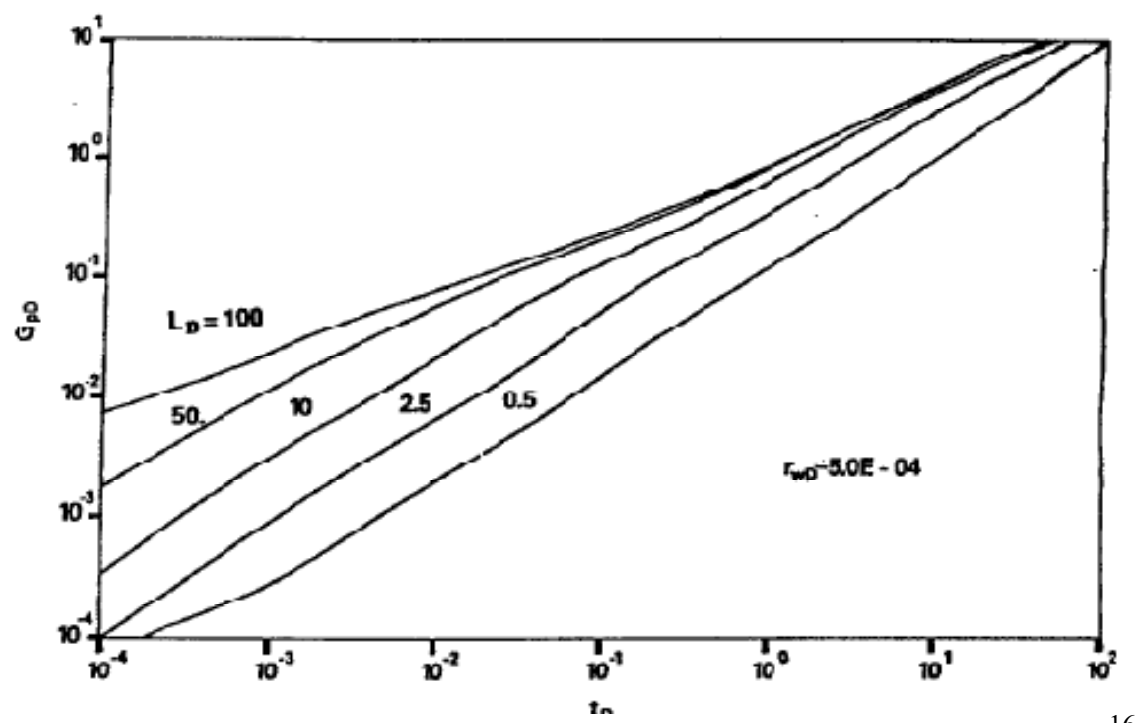

Figure 4. Type Curve for Horizontal Wells in Infinite Reservoirs ${ }^{16}$ 


\subsection{Formation of Coal}

Coal begins when plants are deposited in swamps, then submerged rapidly enough to limit oxidation but to allow microbial decomposition. Shallow waters of a constant depth, such as created between fluvial systems in plains along the coast of seaways or behind coastal barriers, allow enough plant mass to accumulate as undisturbed peat and subsequently covered with sediment.

The peatification process continues as the decomposing plants are progressively covered with sediments, physical processes act to compress, and biochemical processes alter the remains in an environment of warm temperatures and abundant rainfall. When the organic mass becomes deeply buried, coalification transforms it through a function of pressure, temperature, and time as shown in Figure 5. Of these parameters, temperature is the most important in the geochemical reactions that occur.

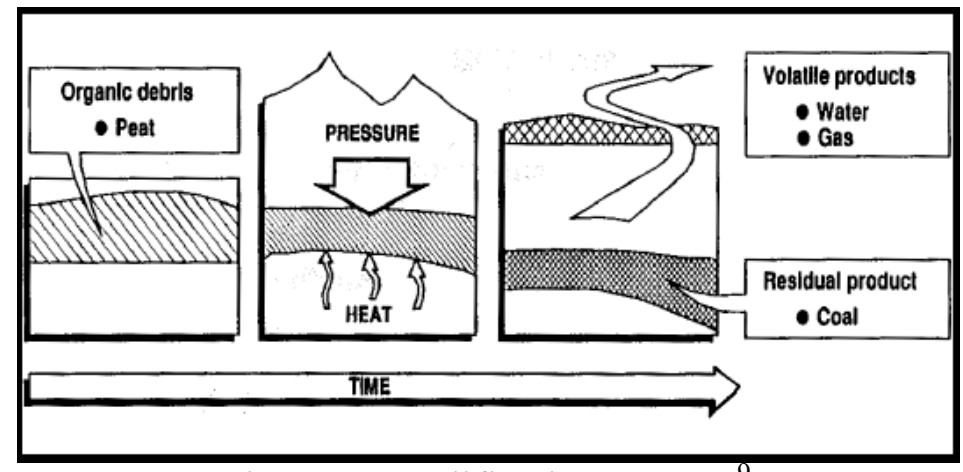

Figure 5. Coalification Process ${ }^{9}$

As temperature and time progressively change the molecular structure of coals, a point is reached where thermogenic methane is evolved in large volumes, micropores develop to store extraordinary amounts of methane per unit of coal, and fractures permeate the coal to transport the excess methane. ${ }^{5}$ Thus, methane is generated to be stored and dissipated over geologic time.

As the coal progresses through the maturation process, physical and chemical properties of the coal change. A rank is used to define these points of maturity. Rank is a portent of success of any prospective CBM project because it implies the potential of gas content, permeability and mechanical and physical properties of the coal. Rank may vary 
content, permeability and mechanical and physical properties of the coal. Rank may vary laterally and vertically within a seam, and it varies from seam to seam within a given coal group. ${ }^{6}$

Designation of rank as a measure of coal maturity is given in Table 2. Coals are divided into lignite, sub bituminous, and anthracitic classes, and further subdivided into an additional 13 groups. Coals of the bituminous class are most sought after for CBM drilling. Specifically, coals of hvAb through lvb are best. In these classes, retention capabilities have been improved and more gas has been generated at this point in the coal maturation process. Also, physical properties and mechanical properties of hvAb through lvb coals have the greatest potential for being a reservoir as shown in Table 2 and Figure 6.

Table 2. ASTM Coal Rank ${ }^{6}$

\begin{tabular}{|c|c|c|}
\hline Class & Group & Abbreviation \\
\hline Anthracitic & Meta-Anthracite & ma \\
\cline { 2 - 3 } & Anthracite & an \\
\cline { 2 - 3 } & Semianthractie & sa \\
\hline Bituminous & Low Volatile & Ivb \\
\cline { 2 - 3 } & Medium Volatile & mvb \\
\cline { 2 - 3 } & High Volatile A & hvAb \\
\cline { 2 - 3 } & High Volatile B & hvBb \\
\cline { 2 - 3 } & High Volatile C & hvCb \\
\hline Subbituminous & Subbituminous A & subA \\
\cline { 2 - 3 } & Subbituminous B & subB \\
\cline { 2 - 3 } & Subbituminous C & subC \\
\hline Lignitic & Lignite A & ligA \\
\cline { 2 - 3 } & Lignite B & ligB \\
\hline
\end{tabular}

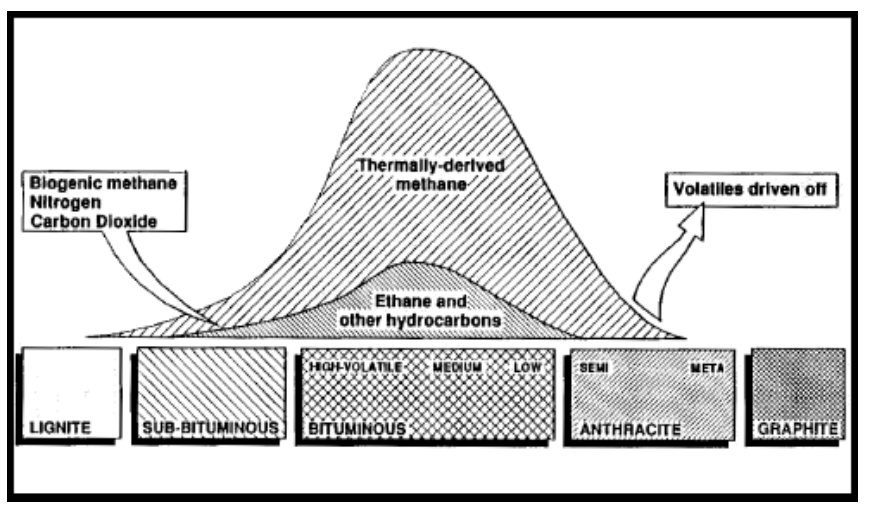

Figure 6. Gas Generation in $\mathrm{Coal}^{9}$ 


\subsection{Adsorption}

Gas produced from coalbeds may be initially higher in methane than the gas produced from conventional reservoirs. Ethane and heavier, saturated hydrocarbons are more strongly absorbed than methane. There is a contrasting difference in the mechanics of gas storage for conventional and unconventional reservoirs. Instead of occupying void spaces as a free gas between sand grains, the methane is held to the solid surface of the coal by absorption in micropores. There is some free gas stored in the natural fractures of the coal and some methane dissolved in the water in the coal, but the bulk of the methane comes from the micropores. The absorption mechanics creates the inconsistency of high gas storage in a reservoir rock with a porosity less than $2.5 \%{ }^{7}$ When the water is removed, lowering the hydrostatic pressure on the coal, the absorbed gas is released. This pressure is called the critical desorption pressure $\left(\mathrm{P}_{\mathrm{c}}\right)$.

The Langmuir equation fits the absorption data of methane on coal and is used exclusively in the CBM process. The model is such a close fit of the absorption data of all coals that the use of the Langmuir equation is universal in the industry. As pressure in the coal seams increase with depth, the capacity of the coal for absorbing more methane improves.

$$
G_{C}=\frac{V_{L} P}{P_{L}+P}
$$

$\mathrm{G}_{\mathrm{C}}=$ Gas Content

$\mathrm{V}_{\mathrm{L}}=$ Langmuir volume constant (Scf/ton)

$\mathrm{P}_{\mathrm{L}}=$ Langmuir pressure constant (psia)

$\mathrm{P}=$ pressure $(\mathrm{psia})$

\subsection{Porosity}

Coal has a dual porosity system. Macropores are the spaces within the cleat system and other natural fractures essential for the transportation of water and methane through seams but are relatively unimportant for methane storage. The storage space of the cleats and other natural fractures contain water, free methane, and methane dissolved in water, but primarily the porosity of the macropores determines the storage capacity for water. 
Coal usually has a porosity ranging from .1 to $10 \%$. Although the coals porosity may be only $2 \%$ in the cleat system, it may have a storage capacity for methane in the mircopores equivalent to that of a $20 \%$ porosity sandstone with $100 \%$ gas saturation at the same depth. ${ }^{11}$ This system allows for a very large volume of methane to be stored in the coal's micropores despite a low porosity percentage.

\subsection{Permeability}

Permeability is the most critical parameter for economic viability of a gas-containing coal. The network of natural fractures must supply the permeability for commercial flow rates of methane. It is also the most difficult parameter to evaluate accurately. Therefore, the frequency of the natural fractures, interconnections, degree of fissure (cracks), aperture direction of butt and face cleats, water saturation, depth, and in-situ stress all have an effect on permeability. ${ }^{12}$

In coalbed methane, there is a two phase flow regime in the interconnected cleat network. When this is present, effective and absolute permeability take place in order to separate the two fluid flows in the porous media. The effective permeability is the ability to preferentially flow or transmit a particular fluid when other immiscible fluids are present in the reservoir. Absolute permeability is the measurement of the permeability conducted when a single fluid or phase is present in the rock. The depth of the coal affects the permeability. According to the Langmuir isotherms of coal, more gas can be absorbed as pressure increase do to depth. Higher formation pressure would be beneficial for gas production but coal's permeability generally decreases with depth.

The characteristics of the cleats are the most important attribute of a gas-containing coal. The fluid moves in a winding path through both butt and face cleats with continuity favoring the face cleat. An increase in the number of cleats per unit volume improves the permeability. Cleat aperture opening as well as length or continuity of the cleat also impacts the permeability. But an issue with high cleat densities creates a brittle coal susceptible to damage from drilling, completions, and hydraulic fracturing. 
The cleat system of coal is a function of the historic tectonic action and its timing, rank, and mineral matter content. Usually low-volatile bituminous coal has the most developed network of cleats. The permeability anisotropy of the butt and face cleat system has a significance in orientation and in spacing of wells. Ideally the horizontal lateral would be orientated perpendicular to the face cleats to intersect the most joints and to increase drainage area. Wells drilled perpendicular to the face cleats are reported to produce 2.5 to 10 times more gas than non-perpendicular wells. ${ }^{13}$

The relative permeability characteristics have significant impact on gas and water production from a coal reservoir because two-phase flow conditions particularly in the early stage of production. A set of published data of relative permeability have been found for a number of coal basins. ${ }^{15,21}$ A set of equations have been used to generalize CBM relative permeability characteristics.

$$
\begin{aligned}
k_{r g} & =k\left(1-S w^{*}\right)^{n \prime} \\
k_{r w} & =\left(S w^{*}\right)^{m \prime} \ldots \ldots
\end{aligned}
$$

To investigate the impact of relative permeability on the type curves, the constants in equations 2.8 and 2.9, the parameters $\mathrm{m}$ ' and $\mathrm{n}$ ' were varied over a range of one to four. The impact of the constant $\mathrm{k}$ was found not to be significant. However, the gas production type curves were found to be influenced by $\mathrm{m}^{\prime}$ and $\mathrm{n}^{\prime} .{ }^{21}$ The exponent n' used in Equation 2.10 is called the Corey Gas Factor and for Equation $2.11 \mathrm{~m}$ ' is the Corey Water Factor.

The relative permeability data for CBM reservoirs are difficult to obtain and cannot be accurately measured in laboratory due to difficulties in obtaining a representative coal samples from the reservoir. The only practical method to obtain realistic relative permeability values is by history matching. If production history has not been initiated or the history production is limited, the relative permeability has to be assumed.

\subsection{Gas Flow}

The difference between conventional and unconventional reservoirs is the mechanism of gas flow though the formation to the wellbore. For coal, an additional mechanism of gas diffusion through the micropores of the coal matrix is involved. The mass transport depends 
upon a methane concentration gradient across the mircopores as the driving force. Upon encountering a fracture or a cleat, the gas will flow according to Darcy's law as in a conventional reservoir where the mass transport depends upon a pressure gradient. ${ }^{8}$

When the well is first drilled, water will fully occupy the cleat space. In the terms of the Langmuir isotherm, the cleats may be under saturated with respect to the gas, and some water must be removed to lower the pressure and initiate desorption as mentioned before. The time period that is required for the pressure disturbance to reach the boundary in Phase I is called infinite acting.

As the water is produced with time, (Phase II), a two-phase flow regime near the wellbore is established. The gas flow in this early two-phase flow regime is followed by pressure drops deeper within the seam as more water is produced. Gas relative permeability improves rapidly as the water saturation increases. In the case of a rectangular drainage area, as soon as the disturbance is created, the well will see the closest boundary first. Then it will see the second boundary, and then it will start the depletion state. A time period where the well has seen one boundary, but not the other, is called the transition time. ${ }^{18}$

The last stage, Phase III, is where both boundaries are seen and after this point the well is producing in a pseudo-steady state. The gas moves through the cleats accompanied by a small amount of water or the water is negligible.

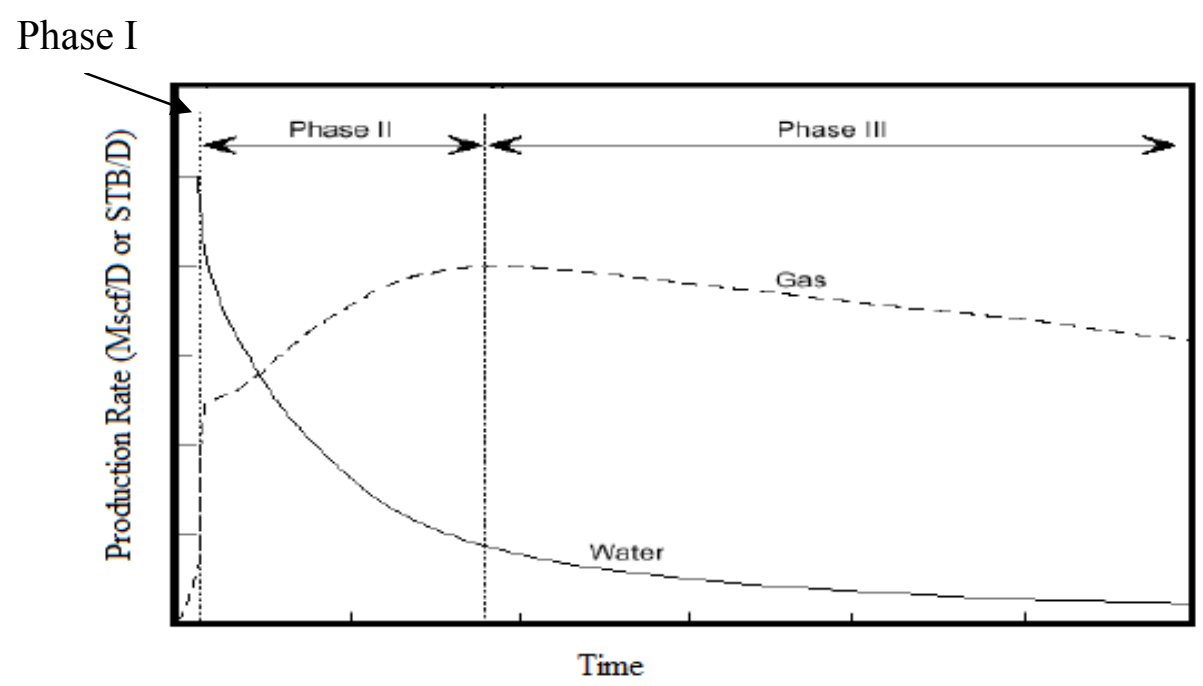

Figure 7. Production Decline for Vertical Well 


\subsection{Type Curves for Coalbed Methane}

The type curve can serve as a simple but yet reliable engineering tool to predict the production performance during the preliminary evaluations. The type curves are not meant to replace reservoir engineering calculations but rather give the operator an idea how the well may produce throughout the life of the well. The type curve can be used for conventional graphical type curve matching in order to determine the reservoir parameters when production history is available. Another way of utilizing the type curve is when the reservoir parameters are already established. In this case, the type curve is used to predict the production performance of the horizontal well.

There has been some research and developments/research for type curves in vertical and conventional wells. To develop a type curve, the production history must be converted to dimensionless rate and time and then plotted in a log-log scale. An example of a type curve for a vertical CBM well is shown in Figure 8. The dimensionless group is used to eliminate the effects of different gas rates, time, and area of the reservoir.

To develop unique dimensionless type curves for unconventional reservoirs, groups of vertical and conventional horizontal wells were evaluated to develop the best match.

The first set of dimensionless groups investigated was:

$$
\begin{aligned}
& t_{D}=\left(\frac{q_{\text {peak }}}{G_{i}}\right) t \\
& q_{D}=\left(\frac{q}{q_{\text {peak }}}\right)
\end{aligned}
$$

In equations 2.12 and $2.13, \mathrm{q}$ is the gas production rate, $\mathrm{q}_{\text {peak }}$ represents the maximum or peak gas rate, and $\mathrm{Gi}$ is the initial gas in place. The initial gas in place can be calculated from the following equation.

$$
G_{i}=43560 A h G_{c}
$$

The reason the coal bulk density is not included in the equation as usual is because the Eclipse modeling program uses different units, Mscf instead of Scf, for $G_{c}$. Therefore the 
bulk density is included with $\mathrm{G}_{\mathrm{c}}$. Equations 2.11 and 2.12 have been used in predicting the performance of vertical CBM wells in previous studies ${ }^{15}$.

The type curves can be used as a quick tool to predict gas production for evaluation of a prospect well. To do this, it is necessary to estimate $\mathrm{q}_{\text {peakD }}$ and $\mathrm{G}_{\mathrm{i}}$ for gas production predictions. Equation 2.13 can be used to calculate Gi. However, estimation of $\mathrm{q}_{\text {peakD }}$ is more complicated due to the two-phase flow conditions. To overcome this problem, the variation of $\mathrm{q}_{\text {peakD }}$ with various parameters was investigated to develop a correlation. First, a dimensionless group for $\mathrm{q}_{\text {peakD }}$ was developed to simplify the correlation. ${ }^{15}$ The dimensionless peak gas rate is defined in Equation 2.14 for vertical wells.

$$
\left(q_{\text {peakD }}\right)=q_{\text {peak }} *\left(\frac{1422 T \mu_{c} z_{c}}{k h\left(P_{c}^{2}-P_{w f}{ }^{2}\right)}\right)\left[\ln \left(\frac{r_{e}}{r_{w}}\right)-0.738+s\right] \ldots \ldots \ldots
$$

In Equation 2.14, $\mathrm{p}_{\mathrm{c}}$ is the critical gas desorption pressure which is the pressure at which gas desorption from the coal matrix into the cleat system begins. It can be determined from the point on the Langmuir isotherm corresponding to the initial gas content. Gas viscosity and z-factor should be estimated from the critical desorption pressure.

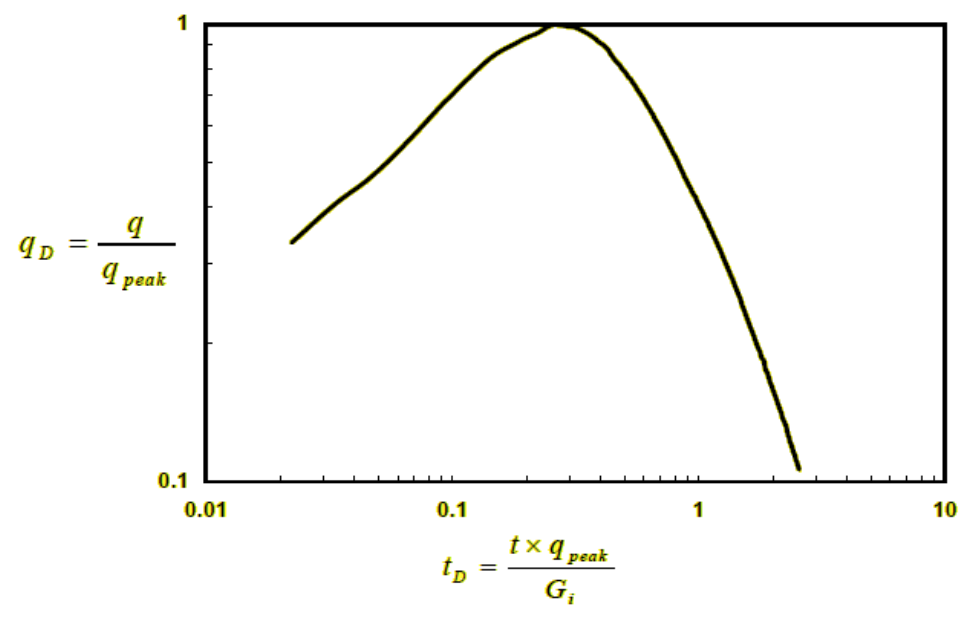

Figure 8. Type Curve for Vertical CBM production 


\subsection{Numerical Models and Assumption}

Production decline curves are usually used to forecast the recovery factor, future revenues, and well performance. The conventional decline curve methods cannot be used to predict CBM production because of the complex nature. Production from CBM reservoirs are controlled by the interaction of gas desorption form the matrix and two-phase flow of gas and water through the cleat system. The performance of CBM can be best predicted by using numerical reservoir systems that account for various mechanisms that control CBM production.

Before the simulation was performed, an intensive literature review was conducted to identify the range of parameters to be used in the base model for the parametric study. When one or more key parameters are not available, it is necessary to perform a Monte Carlo simulation to establish a reliable estimate of production potential to evaluate the risk. Monte Carlo methods are a class of computational algorithms that rely on repeated random sampling to compute their results. Because of their reliance on repeated computations and random or pseudo-random numbers, Monte Carlo methods are most suited for calculation by a computer. However, it is time consuming, costly, and cumbersome to conduct Monte Carlo simulation or parametric studies with a reservoir simulator.

After the literature review was conducted and the parameters established, the best model to use was the Schlumberger Eclipse Reservoir Simulator. Although the "Eclipse Office" CBM template is not a dual porosity model, it models a single porosity reservoir with desorption. With desorption present the model represents accurate and realistic results.

The Coalbed Methane Template model allows you to quickly set up an Eclipse model. With the coalbed methane template, the user can set up a reservoir simulation model without knowledge of the simulator input files or keywords. It allows the user to set up models with relatively simplified geology to study advanced well completion designs with no mapping required. It can be used to study the comparative value of simple vertical completions, hydraulic fracture enhancements, and single or multi-lateral horizontal completions. 
The coalbed methane template consists of the following workflow sections ${ }^{17}$ :

- Model definition

o Model Title

o Simulation Length and Reporting

o Model Parameters

- Reservoir Description

- Layers

- Rock Properties

- Rock Name

- Fracture Porosity

- Bulk x, y, and $\mathrm{z}$ direction permeability

- Compressibility

- Non-Equilibrium Initial conditions for the whole reservoir

- Reservoir Pressure

- Water Saturation

- Coal Gas Concentration

- Aquifers

- Fractures

- Wells - well deviation

- Production

o Well Controls

o Perforation

o Limits

- BHP

- Fluid Properties

o PVT Composition

o Relative Permeability

o Coalbed Methane

- Fluid Property

- CBM properties input

- User-defined Langmuir input

- Simulation Controls

The initial coal gas concentration is an optional input. By default the initial coal gas concentration is defined by the Langmuir Isotherm which defines the relationship of gas concentration as a function of pressure. In the non-equilibrium initialization case pressure is constant. The initial coal gas concentration input can be used to define an under-saturated coal. In an under-saturated coal case, gas will not be desorbed from the coal until the 
pressure drops below the saturation pressure. The saturation or equilibrium pressure will be defined as the Langmuir pressure that corresponds to the input of the initial coal gas concentration.

The coalbed methane option in Eclipse assumes that the gas absorbed within the coal matrix diffuses to the matrix-fracture interface and subsequently desorbs into the fracture network using a Langmuir Isotherm as a boundary condition. The concentration of gas absorbed on the coal surfaces at the matrix-fracture interface is assumed to be a function of pressure only, as described by the Langmuir equation. The movement of gas from within the coal matrix to the fracture is described with a diffusive flow equation. 


\section{OBJECTIVE AND METHODOLGY}

The objective of this research was to develop production type curves for horizontal wells in unconventional reservoirs. This will be achieved by the following steps:

1. Development of a basic reservoir model to predict gas production profiles for horizontal wells completed in a CBM reservoir.

2. Evaluate the impact of various reservoir parameters on the type curves.

3. Development of sets of production type curves for horizontal wells in CBM reservoirs.

4. Development of a methodology to use type curves as a tool for predicting gas production from CBM reservoirs.

5. Investigate the application to unconventional shale reservoirs.

\subsection{Base Model Development and Assumptions}

The base model was developed for an under-saturated CBM reservoir with the well configuration as shown in Figure 9. The parameters used to develop the base model were selected from previous publications. ${ }^{15}$ The area of 83 acres was used for the simplicity for entering the length and width into the simulator that would give a ratio of 2 to 1 . The base model was developed from the horizontal well shape factor because the drainage area shape $(\mathrm{Xe} / \mathrm{Ye})$, well penetration $(\mathrm{L} / \mathrm{Ye})$, and dimensionless well length $\left(\mathrm{L}_{\mathrm{D}}\right)$ are all major parameters in the production analysis development. The permeabilities are also different for the $\mathrm{x}$ and $\mathrm{y}$ directions to model the face and butt cleats. As a result of coal being anisotropic, the horizontal well was drilled perpendicular to the direction with the highest permeability, that is, in the y-direction. All the parameters can be seen in Table 4. 


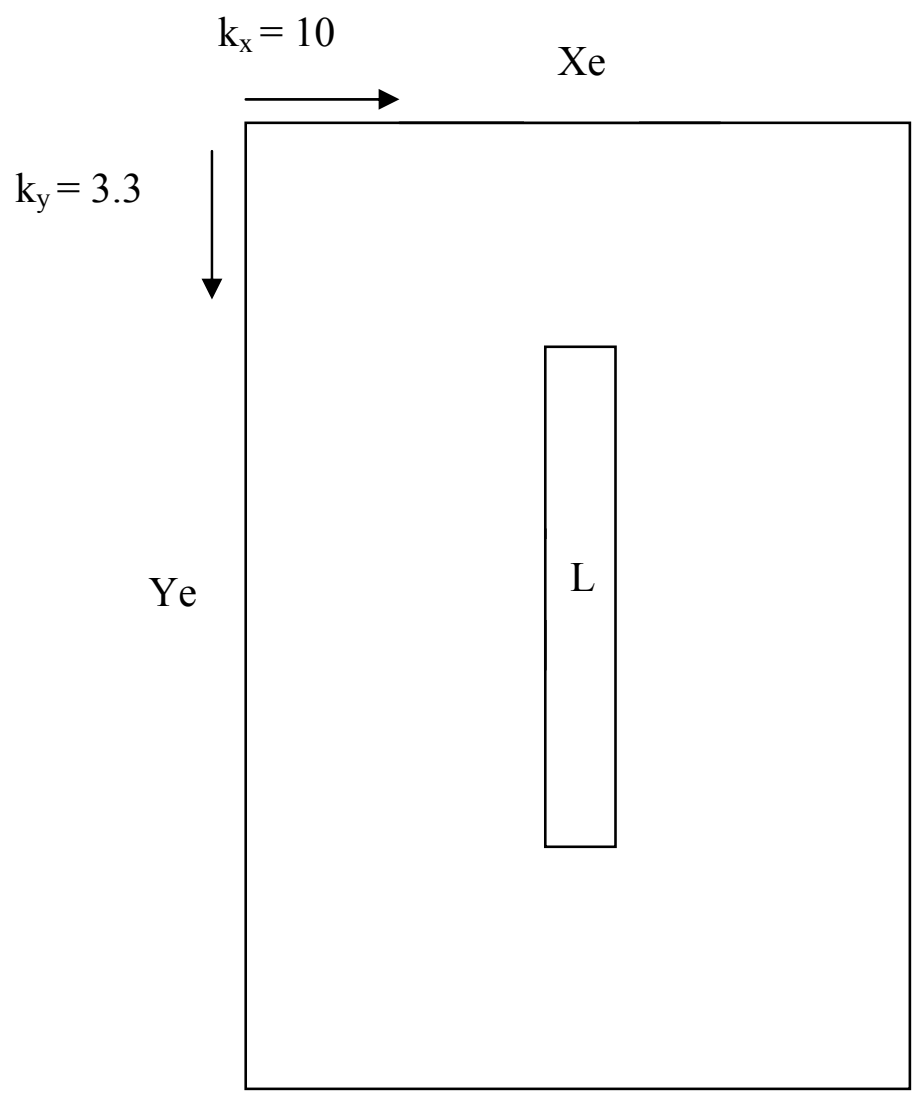

Figure 9. Base Case Model

\subsection{Model Parameters}

In order to establish the unique type curves, the impact of the reservoir parameters were investigated. Parameters were changed through a range of values in order to compare the different drainage areas using the same L/Ye ratio while changing one variable at a time. Throughout the investigation the critical desorption pressure was held constant at 350 psia. The permeability values for each direction were changed at a constant ratio of 1:3 (1/3 of the maximum permeability; $\mathrm{x}=3.3 \mathrm{md}, \mathrm{y}=10 \mathrm{md}$ ). The simulation was run with varying the permeability ranging from 5 to $20 \mathrm{md}$ in the y-direction. The relative permeability characteristics have significant impact on gas and water ( $n^{\prime}$ and $\left.m^{\prime}\right)$ production because of the two-phase flow conditions. Also, Langmuir pressure has a significant impact until the Langmuir pressure is above or equal to the reservoir pressure since the pressure is equivalent to where the gas is desorbed. 
The list of parameter changes can be seen below in Table 3.

Table 3. Values and Ranges of Parameters used in Model

\begin{tabular}{|c|c|c|}
\hline PARAMETERS & Range & Values used \\
\hline Reservoir Shape & Rectangle & Rectangle \\
\hline Area (acres) & $41-157$ (Rectangle) & $41,83,157$ \\
\hline Lateral length Ratio (L/Ye) & $0.25-1$ & $0.25,0.5,0.75,1$ \\
\hline Rectangle Lateral Length (ft) & $475-2680$ & $\begin{array}{c}40 \text { acre }-(475,950,1425) \\
80 \text { acre }-(675,1350,2025,2680) \\
160 \text { acre }-(1850)\end{array}$ \\
\hline Fracture Porosity (\%) & $1-2$ & $1,1.5,1.7,2$ \\
\hline Permeability x,y (mD) & $8-20,2.7-6.7$ & $(8,2.7),(10,3.3),(15,5),(20,6.7)$ \\
\hline Langmuir Pressure (psia) & $200-800$ & $200,400,600,675.6,800$ \\
\hline Langmuir Volume (scf/ton) & $476-600$ & 476,600 \\
\hline
\end{tabular}

\subsection{Evaluating Different Dimensionless Groups for Type Curve Development}

Having different flow regimes from vertical wells, one unique type curve will not be sufficient or accurate. The assumption is that two different dimensionless groups will be needed. The first dimensionless group will be needed for the first phase (linear flow) up to the peak gas production. Once the next flow regime is reached (elliptical) another dimensionless group will be used to predict the rest of the wells life.

When developing the unique type curves, equations 2.3 thru 2.6, 2.12, and 2.13 were used to generate different sets of curves. After evaluating the different dimensionless groups the results verified that there was a need to have two different sets of unique type curves. This is a result of the two flow regimes that the horizontal well encounters during production.

The first dimensionless group represents the linear flow regime. As described before the linear flow is present up to the peak production. When evaluating the different dimensionless groups, there was not a unique type curve to match the production during the linear flow phase. A different set of dimensionless group were developed for the linear flow by multiplying $t_{D}$ (equation 2.12) with $\mathrm{L}_{\mathrm{D}}$ (equation 2.7). 
Table 4. Input Parameters for Base Case Model

\begin{tabular}{|c|c|c|}
\hline Input Parameters & Horizontal Model & Value \\
\hline Period of Production & - & 25 years \\
\hline Porosity Model & \multicolumn{2}{|c|}{ Single Porosity with Desorption } \\
\hline Model Geometry & \multicolumn{2}{|c|}{ One Layer -2D } \\
\hline Grid Size & - & $100 \mathrm{ft} \times 100 \mathrm{ft}$ \\
\hline Reservoir Area & - & 83 acres \\
\hline Shape & - & Rectangle \\
\hline Lateral Length & - & $1350 \mathrm{ft}$ \\
\hline \multirow{17}{*}{ Reservoir Parameters } & Depth & $1200 \mathrm{ft}$ \\
\hline & Thickness & $12 \mathrm{ft}$ \\
\hline & Length (Ye) & $2700 \mathrm{ft}$ \\
\hline & Width (Xe) & $1350 \mathrm{ft}$ \\
\hline & Fracture Porosity & $0.017 \mathrm{mD}$ \\
\hline & Bulk X-direction Permeability & $3.3 \mathrm{mD}$ \\
\hline & Bulk Y-direction Permeability & $10 \mathrm{mD}$ \\
\hline & Bulk Z-direction Permeability & $1 \mathrm{mD}$ \\
\hline & Coal Compressibility & $1.00 \mathrm{E}-06$ \\
\hline & Rock Density & $89.63 \mathrm{lb} / \mathrm{ft}^{3}$ \\
\hline & Reservoir Pressure & 650 psia \\
\hline & Water Saturation & $100 \%$ \\
\hline & Coal Gas Concentration & $0.00728 \mathrm{Mscf} / \mathrm{ft}^{3}$ \\
\hline & Reference Temperature & $90 \mathrm{~F}$ \\
\hline & Gas Gravity & 0.7 \\
\hline & Reference Pressure & 650 psia \\
\hline & Maximum Pressure & 780 psia \\
\hline \multirow{8}{*}{ Relative Permeability } & Corey Gas Factor & 2 \\
\hline & Sgrw & 0 \\
\hline & $\operatorname{Krg}($ Swmin) & 1 \\
\hline & Corey Water Factor & 3 \\
\hline & Swmin & 0.3 \\
\hline & SwCrit & 0.3 \\
\hline & Krw (Sgrw) & 1 \\
\hline & Kr (100\% Sat) & 1 \\
\hline \multirow{6}{*}{ Coal Bed Methane } & Gas Diffusion Coefficient & $1 \mathrm{ft}^{2} /$ day \\
\hline & Gas Desorption Time & 30 days \\
\hline & Critical Desorption Pressure & 350 psia \\
\hline & Coal Re-absorption Factor & 1 fraction \\
\hline & Langmuir Pressure & 675.6 psia \\
\hline & Langmuir Concentration & $0.0213 \mathrm{Mscf} / \mathrm{ft}^{3}$ \\
\hline Production Limits & Bottom Hole Pressure & 80 psia \\
\hline
\end{tabular}


The production is dependent on the length of the well when it is in the linear flow regime. Regardless of the reservoir area, if the lateral length or L/Ye ratio are the same the type curves match for the linear phase only as shown in Figure 10.

The second dimensionless group represents the elliptical/radial flow regime. It is present after the peak production rate to the end of the wells life. When evaluating the different dimensionless groups, the group that had the best match has been used in previous research

for vertical CBM production predictions. This unique match is because the horizontal well flow is similar to that of a vertical well. Equations 2.12 and 2.13 represent the best type curve for the second flow regime as shown in Figure 11.

\subsection{Methodology for Application of Type Curve for Production Prediction}

It is necessary to estimate $\mathrm{q}_{\text {peakD }}$ for gas production predictions as explained earlier. The equation defines the dimensionless peak gas rate for horizontal wells as:

$$
\left(q_{\text {peakD }}\right)=q_{\text {peak }} *\left(\frac{1422 T \mu_{c} z_{c}}{k h\left(P_{c}{ }^{2}-P_{w f}{ }^{2}\right)}\right)\left[\ln \left(\frac{r_{e}}{r_{w}}\right)-0.738+s+s_{C A}-c^{\prime}\right] \ldots \ldots \ldots \ldots . .
$$

A linear multiple regression analysis was performed to develop the correlation. To achieve the best fit, reservoir parameters with significant impact on $\mathrm{q}_{\text {peakD }}$ were correlated in various combinations. The parameter used were porosity, critical desorption pressure, Langmuir pressure and volume, $\mathrm{ky} / \mathrm{kx}$ ratio, and $\mathrm{L} / \mathrm{Ye}$ ratio. The selections of these parameters are important because the gas production relies on these reservoir parameters. 


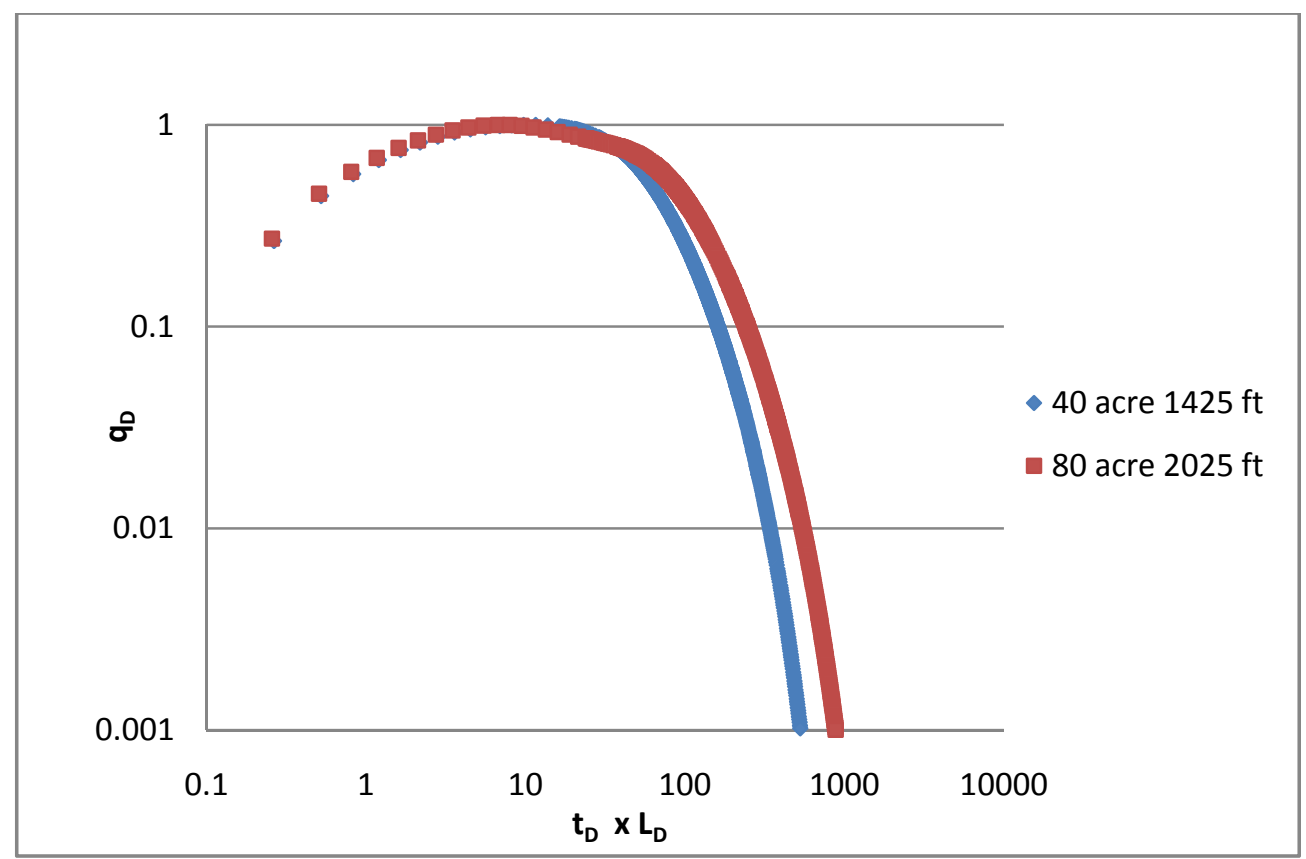

Figure 10. Type Curve Development for Early Production

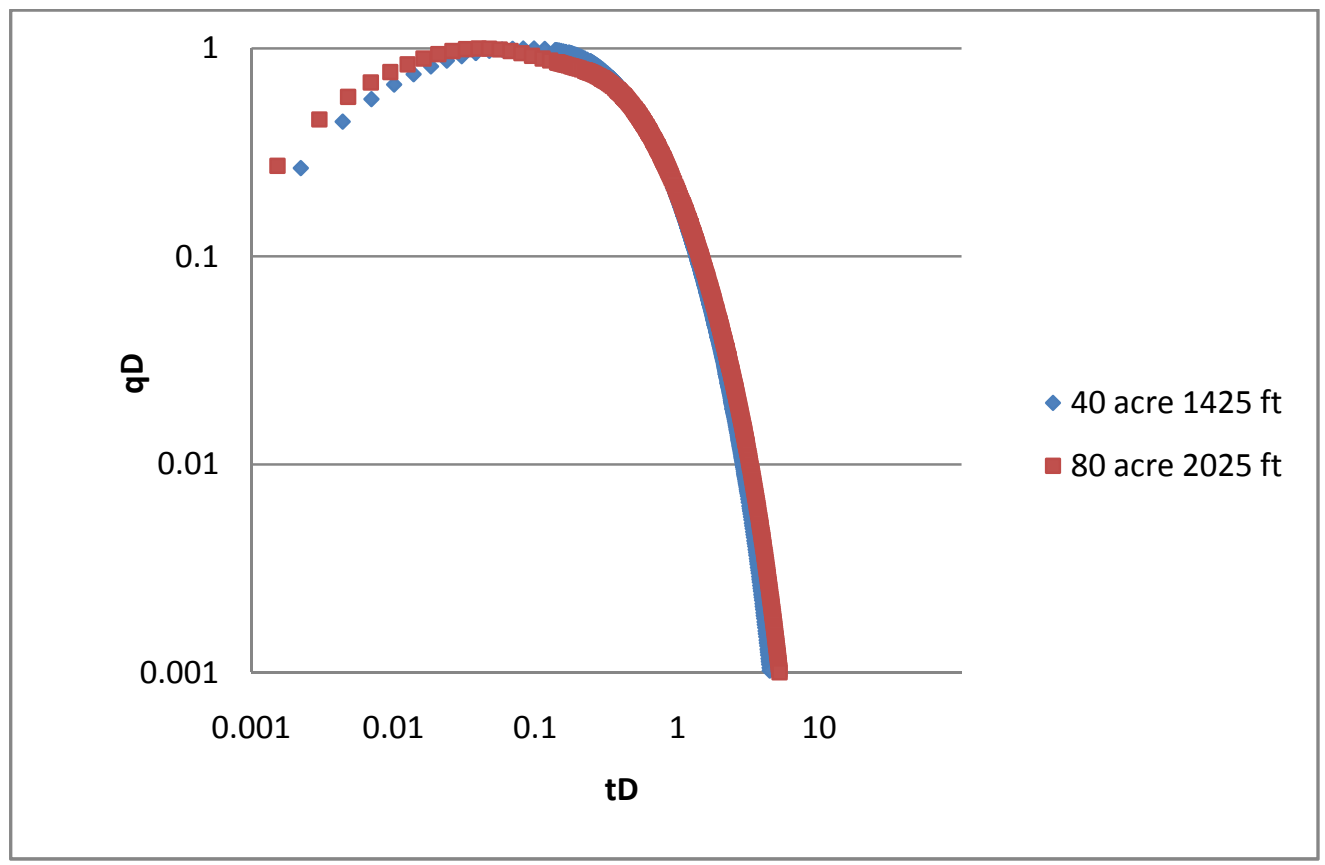

Figure 11. Type Curve Development for Late Production 


\subsection{Case study for Verification}

To evaluate the reliability of the gas production type curves and the correlations for $\mathrm{q}_{\text {peakD }}$, a case study was performed. A set of reservoir characteristics summarized in Table 5 were used as inputs into the reservoir simulator to generate the production history. These production histories were used to compare against the predictions from the type curves using the peak gas rate.

Table 5. Input data for Case Study

\begin{tabular}{|c|c|}
\hline Parameters & Values \\
\hline Fracture Permeability (x, y) (md) & 12,4 \\
\hline Fracture porosity (\%) & 1.7 \\
\hline Area (ac) & 100 \\
\hline Thickness (ft) & 12 \\
\hline Critical desorption pressure (psi) & 260 \\
\hline Reservoir Pressure (psi) & 650 \\
\hline Langmuir Pressure (psi) & 500 \\
\hline Langmuir Volume (Mscf/ft $\left.{ }^{3}(\mathrm{scf} / \mathrm{ton})\right)$ & $0.0213(476)$ \\
\hline $\mathrm{L}(\mathrm{ft})$ & 2222 \\
\hline $\mathrm{Xe}(\mathrm{ft})$ & 1475 \\
\hline Ye (ft) & 2950 \\
\hline
\end{tabular}

\subsection{Application to Shale}

After the two sets of dimensionless groups were developed for the unconventional CBM reservoir a comparison was completed with an unconventional shale reservoir. This was evaluated by first making simulation runs with the CBM template starting at equilibrium. These comparisons were run to see if the dimensionless groups used would also have similar unique type curves for a shale reservoir.

The same parameters used for the equilibrium CBM run were then used in the Eclipse Office Shale template. The dimensionless groups did not show any results for a unique type curve. Even though CBM and shale are both unconventional reservoirs, both have adsorbed gas in their respective matrix and the adsorbed gas is released by lowering the reservoir pressure, there is no similarities in the type curves. There will have to be further studies and 
research completed to develop an accurate and reliable set of type curves for a shale reservoir.

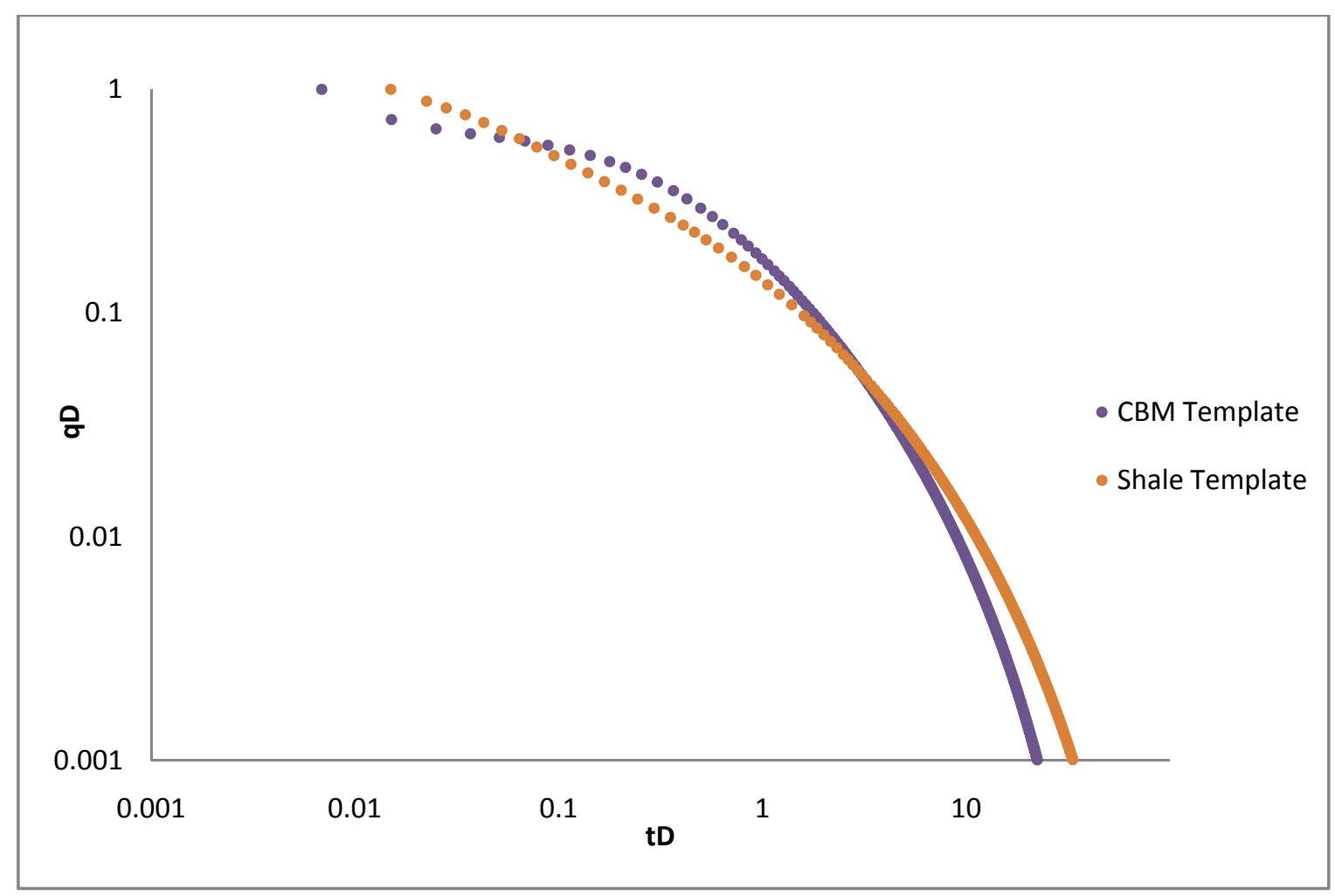

Figure 12. Comparison of CBM and Shale Template Model 


\section{RESULTS AND DISCUSSION}

The CBM production prediction tool developed in this study can serve as a quick and reliable tool for production performance, prediction, and production data analysis. The results of the impact of the various parameters are shown below for all rectangular drainage area.

The first set of simulations took into account the effect of porosity on the production from horizontal CBM wells. The porosity was varied from a range of $1 \%$ to $2 \%$.

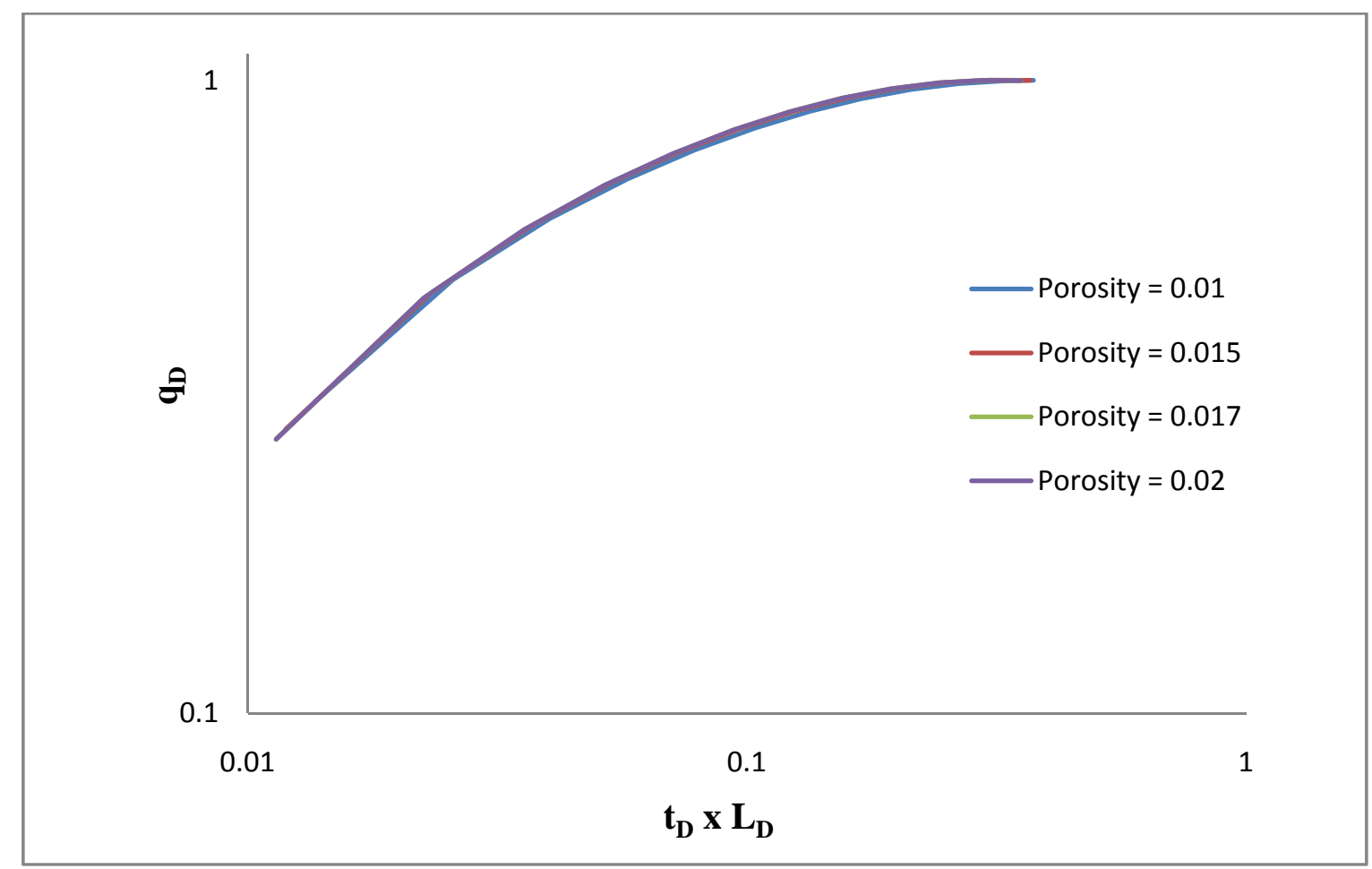

Figure 13. Impact of the Porosity Variation on the Type Curve for Early Production

Figure 13 illustrates the effect of the porosity change for the linear flow regime on the type curve. Although the porosity is the primary source for methane storage in the micropores the effect of variation on the porosity is minimal when the dimensionless groups were introduced 
for both the early and late production. Figure 14 illustrates the effect of the porosity in the elliptical flow regime.

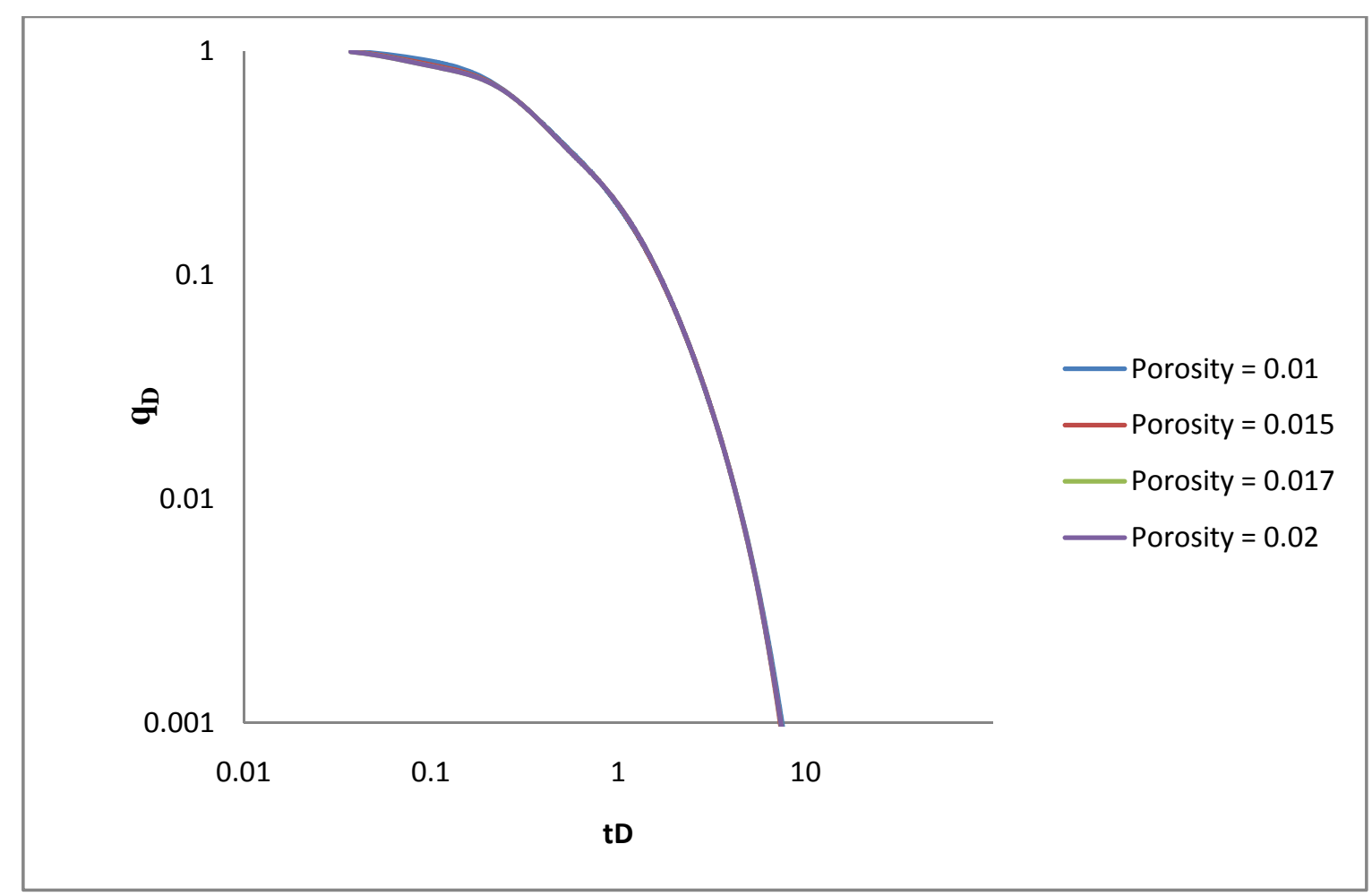

Figure 14. Impact of the Porosity Variation on the Type Curve for Late Production

Figure 15 shows the impact of $\mathrm{L} / \mathrm{Ye}$ ratio for the linear flow regime on the type curve. As mentioned previously, if the formation height is small, or if $\mathrm{k}_{\mathrm{v}} / \mathrm{k}_{\mathrm{H}}$ is small, the early radial flow may not be present. The model developed for production uses a single layer reservoir so there is no gas flow from the vertical permeability. So the transient reaches the upper and lower boundaries when the pressure is reduced to the critical pressure and the production flow is linear toward the well within the horizontal plane.

The production is dependent on the length of the well when it is in the linear flow regime. Regardless of the drainage area, if the $\mathrm{L} / \mathrm{Ye}$ ratio are the same the type curves match for the corresponding $\mathrm{L} / \mathrm{Ye}$ ratio for early and late production. 
Figure 16 thru 18 shows the impact of L/Ye ratio for the elliptical flow regime on the type curve. The third regime, late-time pseudo-radial flow, occurs as the transient moves so far from the well that flow becomes radial again, but this time in the horizontal plane. The dimensionless group used has been in previous research for vertical CBM production prediction. This unique match is also adequate for predicting the late production for horizontal wells because the pseudo-radial flow is similar to that of a vertical wells production.

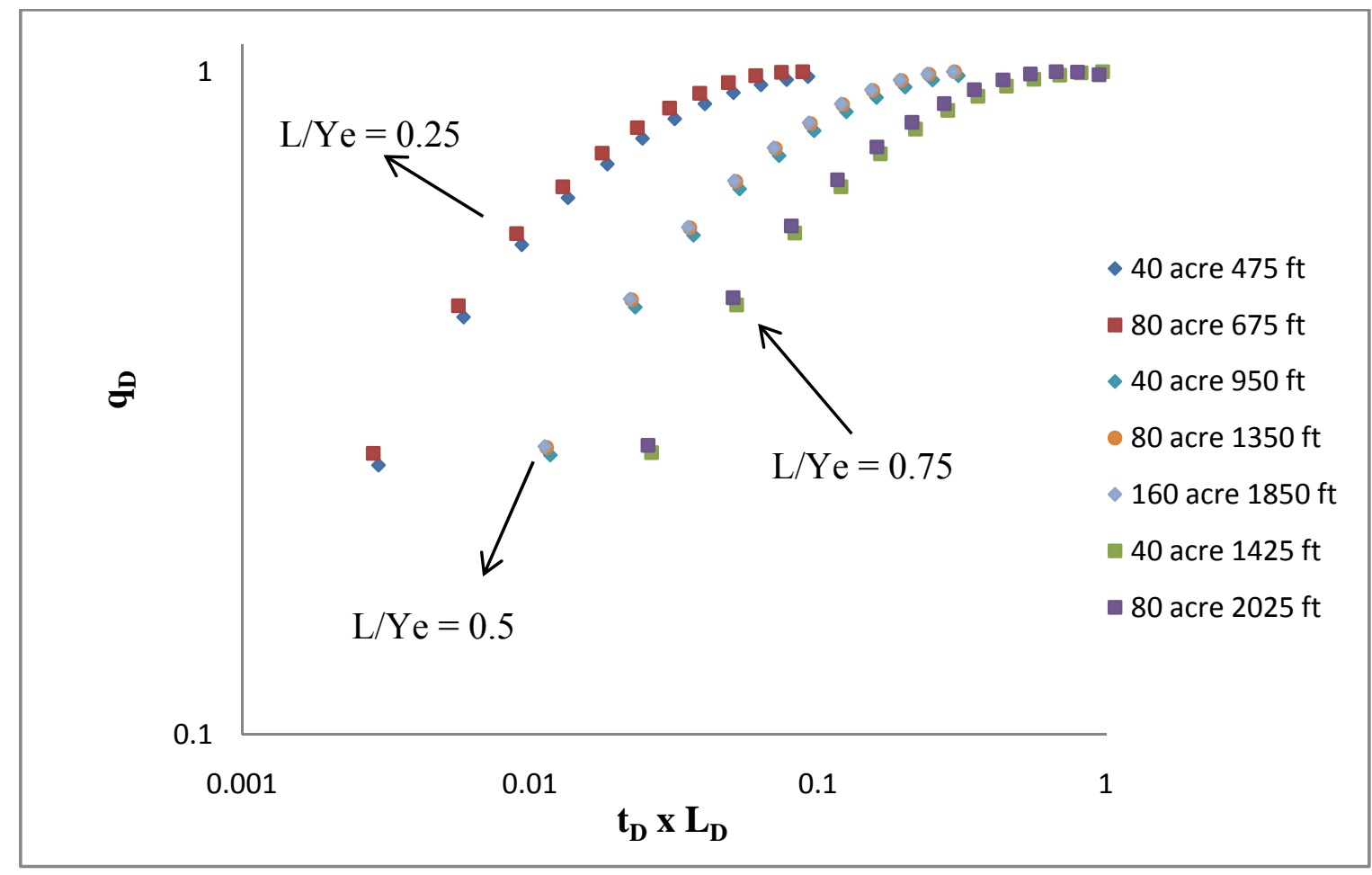

Figure 15. Impact of Drainage area when Comparing L/Ye ratio 


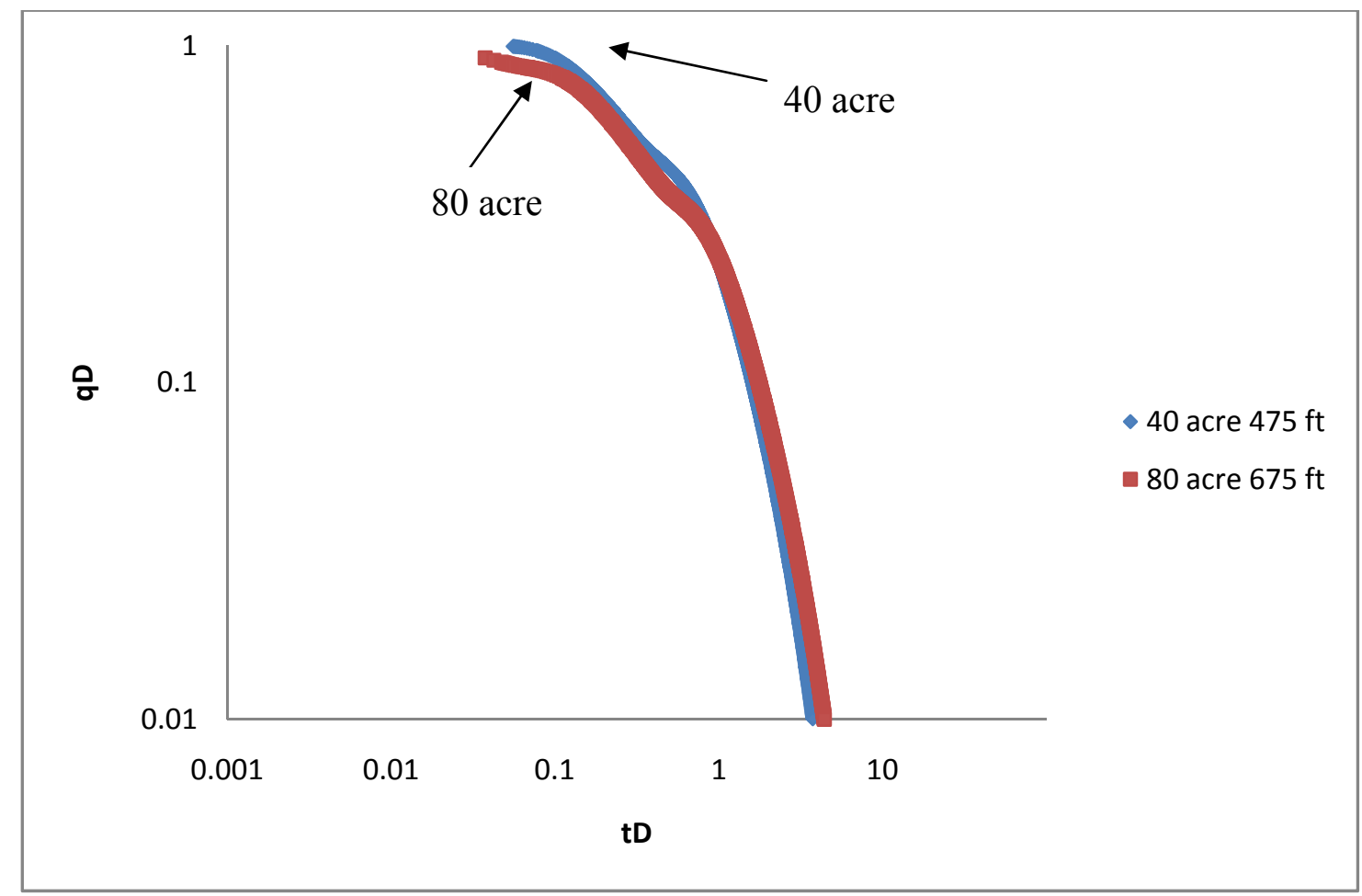

Figure 16. Impact of Drainage Area on the Type Curve when Comparing L/Ye $=0.25$ for Late Production

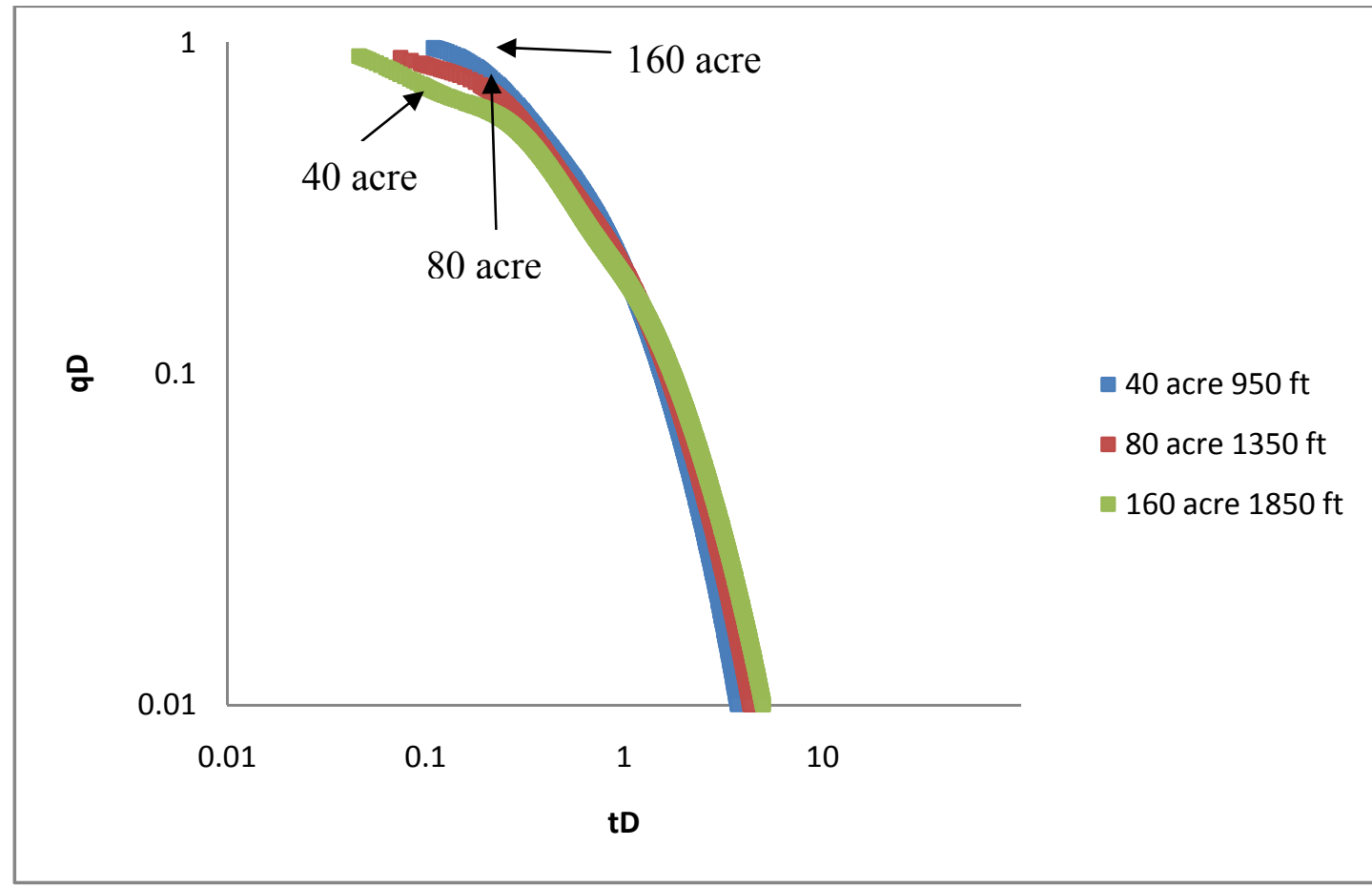

Figure 17. Impact of Drainage Area on the Type Curve when Comparing L/Ye $=0.5$ for Late Production 


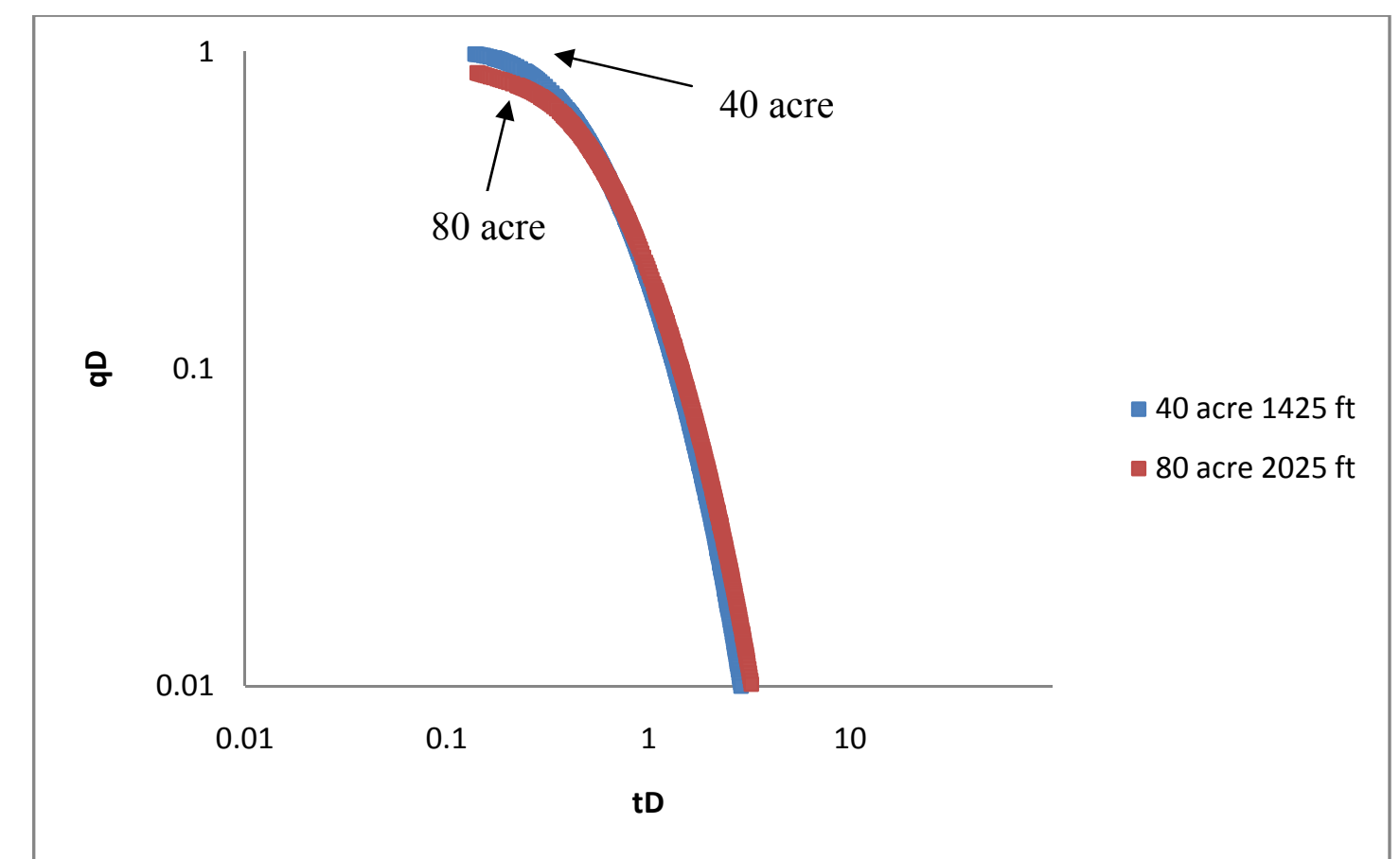

Figure 18. Impact of Drainage Area on the Type Curve when Comparing L/Ye $=0.75$ for Late Production

Figure 19 shows the impact of permeability change for the linear flow regime in loglog scales. The impact of permeability anisotropy was investigated since coals cleat system is characterized by two fracture systems. Generally the permeability in the face cleat direction is higher than the permeability in the butt cleat direction. Several variations for permeability were run and the results did not indicate any significant deviation on the type curve. Figure 20 shows the impact of the permeability change for the elliptical flow regime on the type curve. 


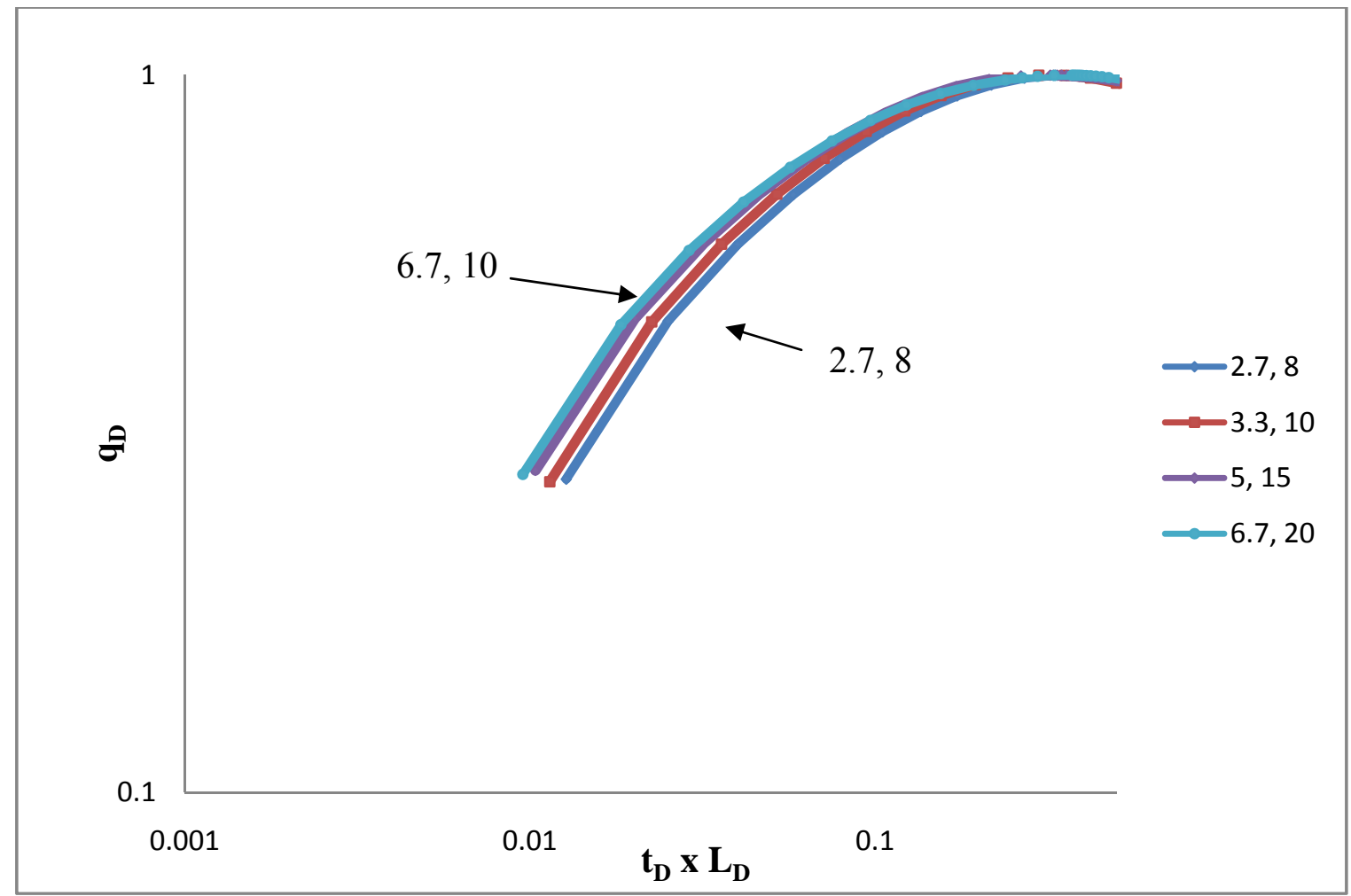

Figure 19. Impact of the Permeability Variation on the Type Curve for Early Production

Figure 21 shows the impact of the linear flow regime production for Langmuir pressure changes on the type curve. Langmuir pressure does result in significant variation on the type curve for the lower pressures. The type curve is still adequate because field data shows that the $\mathrm{P}_{\mathrm{L}}$ value is normally similar to the reservoir pressure. The reservoir pressure for the base case was 650 psia, the type curve is unique for the Langmuir pressures above 600 psia and gives accurate production predictions when used in linear multiple regression correlation. Figure 22 shows the impact of Langmuir pressure on the type curve for elliptical flow regime. The type curve for the elliptical flow regime also verifies the same results as the linear flow. 


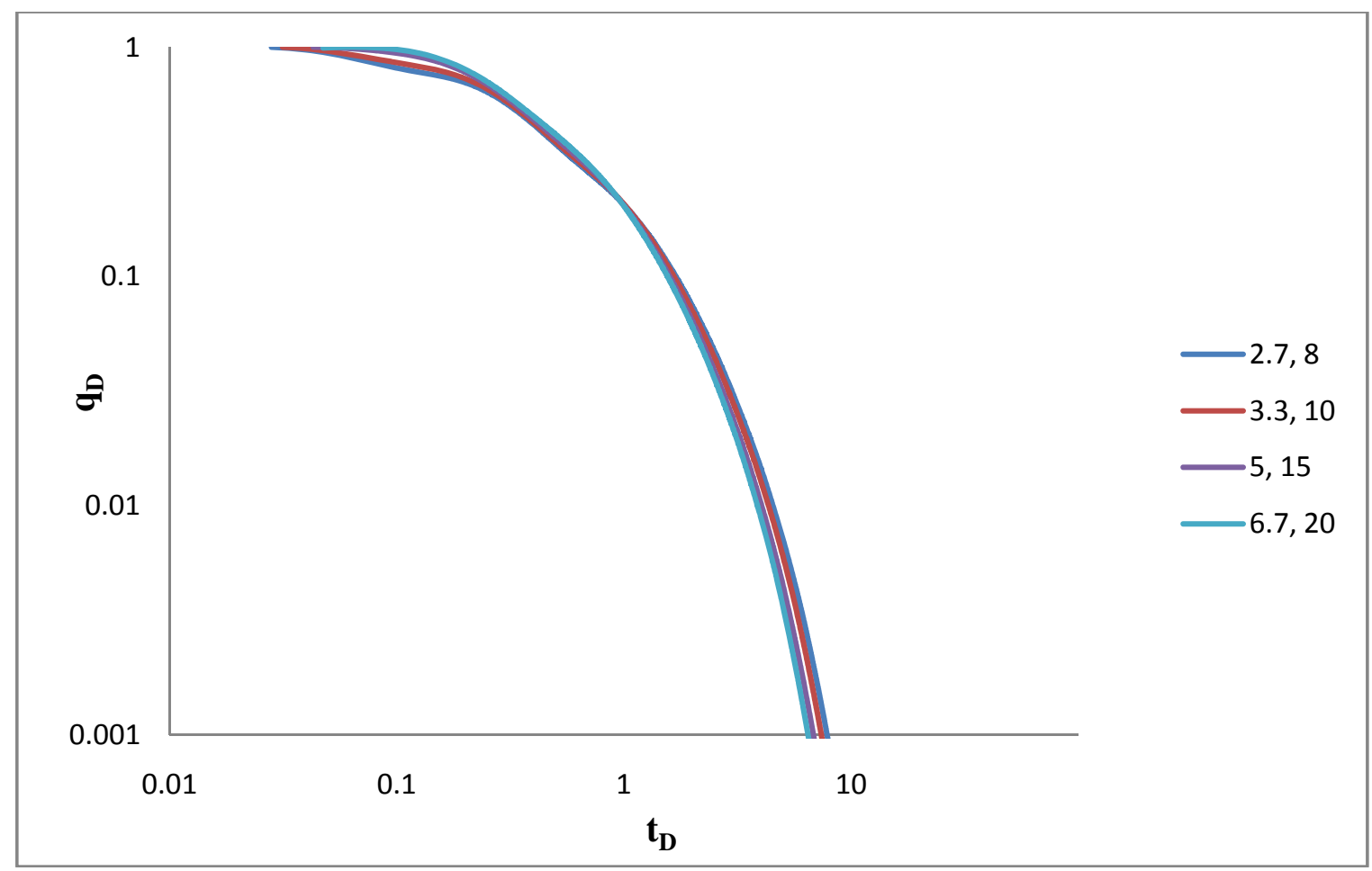

Figure 20. Impact of the Permeability Variation on the Type Curve for Late Production

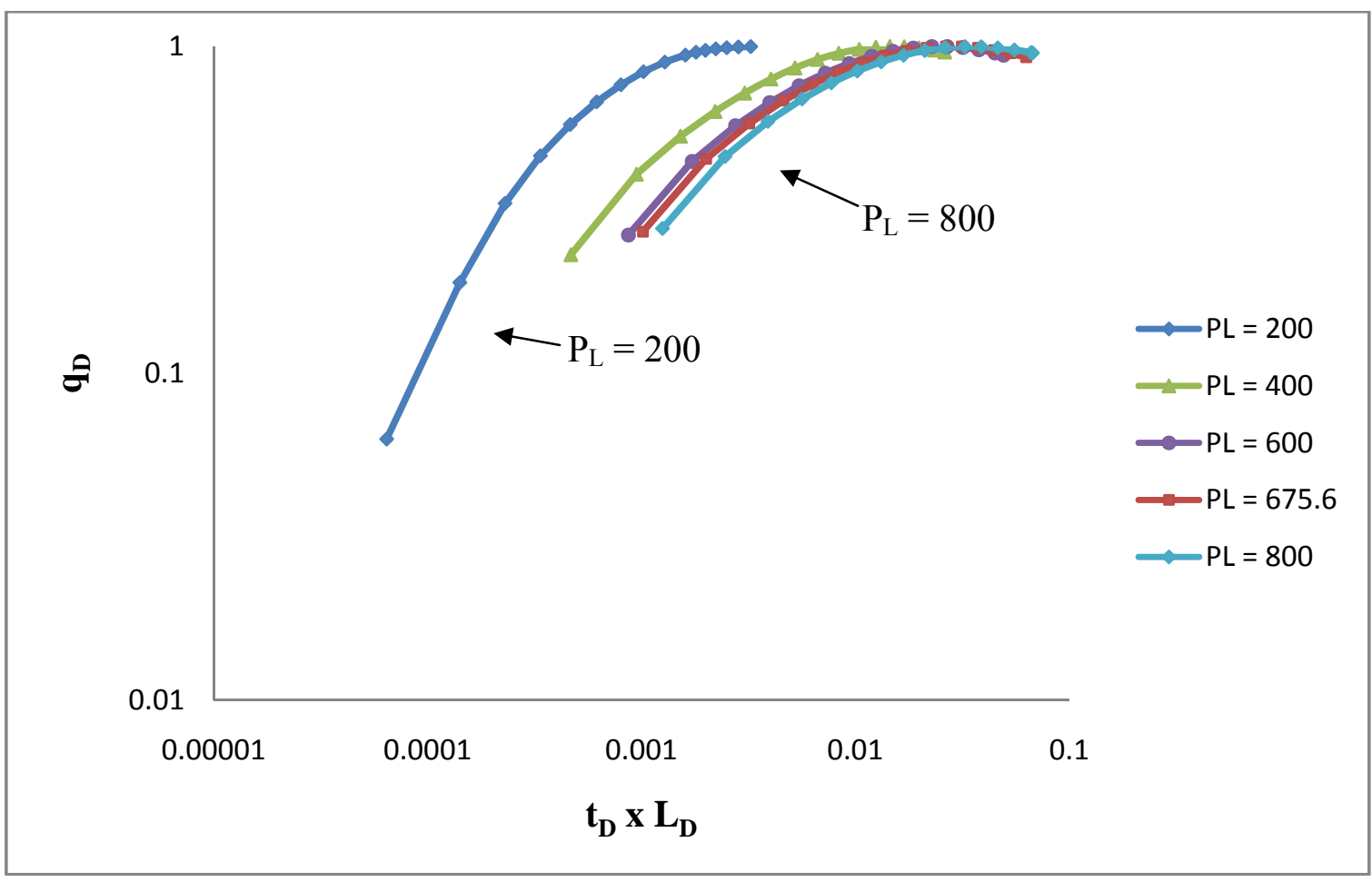

Figure 21. Impact of Langmuir Pressure Changes on Type Curves for Early Production 


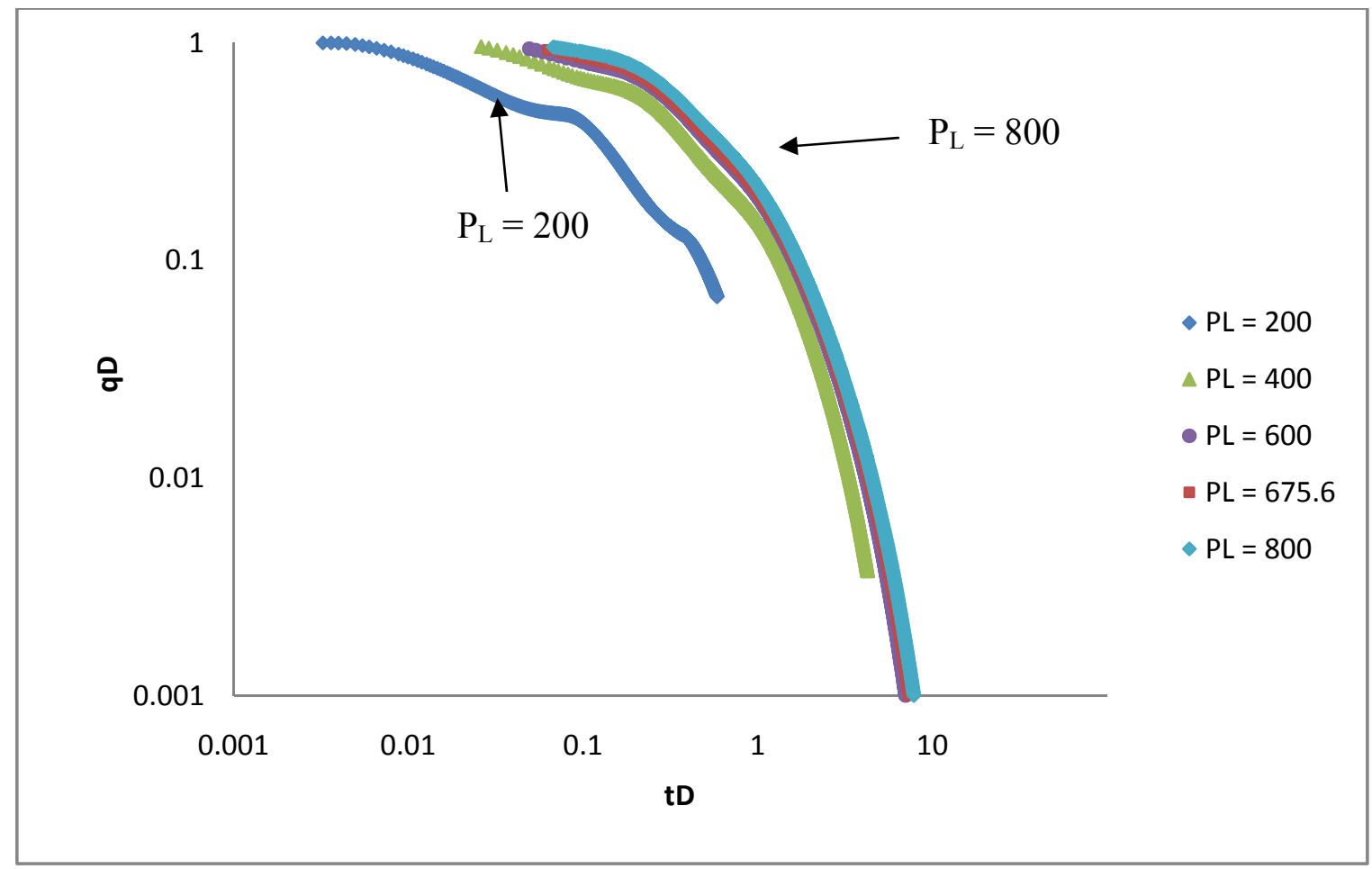

Figure 22. Impact of Langmuir Pressure Changes on Type Curves for Late Production

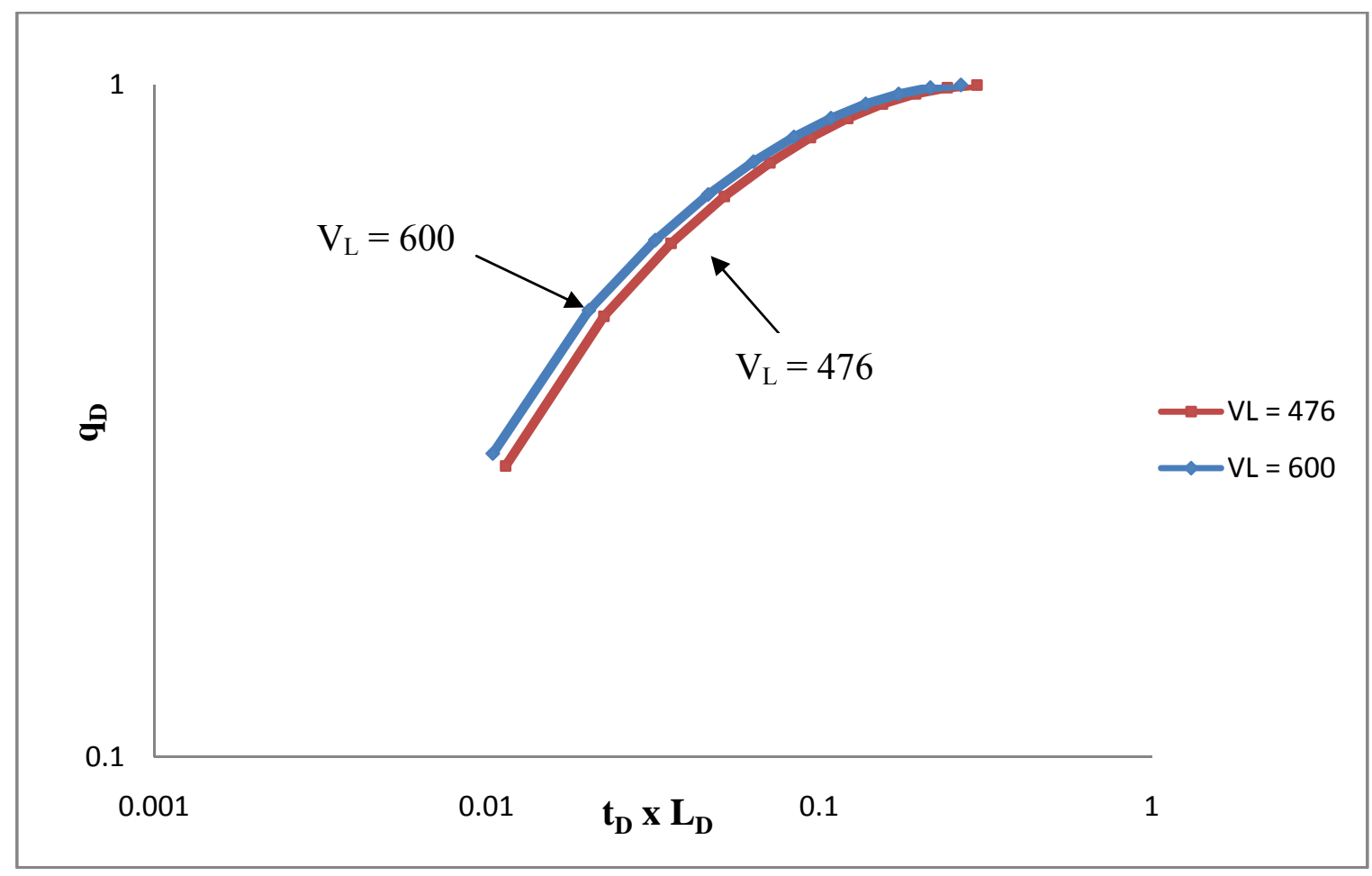

Figure 23. Impact of Langmuir Volume Changes on Type Curves for Early Production 


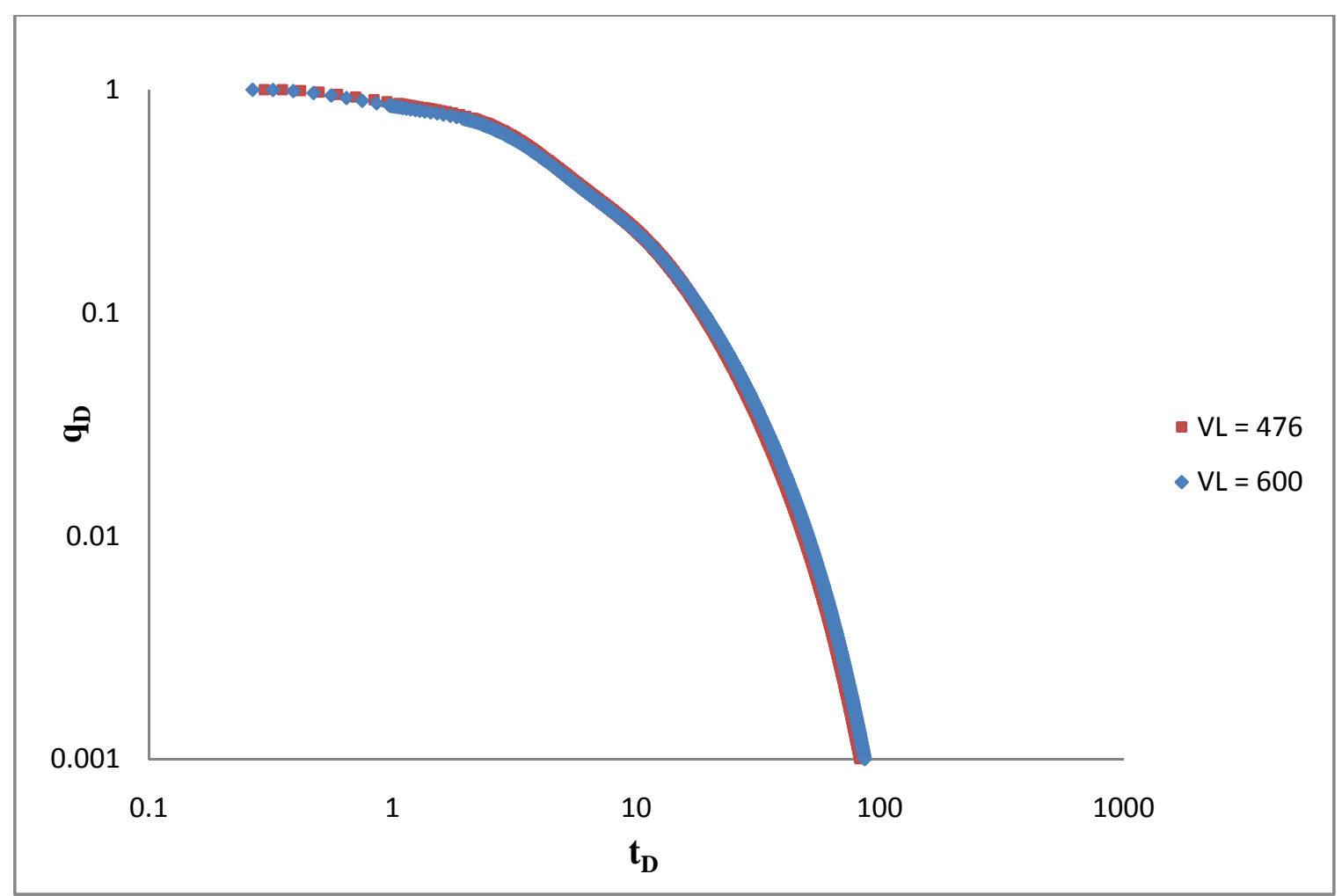

Figure 24. Impact of Langmuir Volume Changes on Type Curves for Late Production

Figure 23 show the impact of Langmuir volume on the type curve for the linear flow regime. The Langmuir volume variations resulted in minor deviation on the type curves for both linear and elliptical flow regimes. Figure 24 shows the impact of Langmuir volume on the type curve for late production.

The type curves show accurate and reliable results so a linear multiple regression was completed as explained previously. Once the parameters were analyzed, a linear multiple regression developed the following correlation $\left(\mathrm{R}^{2}=0.76\right)$ :

$$
\begin{gathered}
\left(q_{\text {peakD }}\right)=5.366 \varphi+3.273 \times 10^{-4} P_{C}+9.134 \times 10^{-5} P_{L}-3.086 \times 10^{-4} V_{L}+0.0457\left(\frac{k_{y}}{k_{x}}\right)- \\
0.41301\left(\frac{L}{2 X e}\right)-0.03878 \ldots \ldots(4.1)
\end{gathered}
$$

By using Equation 4.1, a reverse calculation of Equation 3.1, the peak gas rate for any case can be calculated. The estimated peak value for the case study was $299.51 \mathrm{Mscf} / \mathrm{D}$, while the simulator gave a peak of $380.71 \mathrm{Mscf} / \mathrm{D}$. This gives a percent error of 21 percent 
at the peak. Figure 25 shows the gas production prediction using the developed type curves vs. stimulation results.

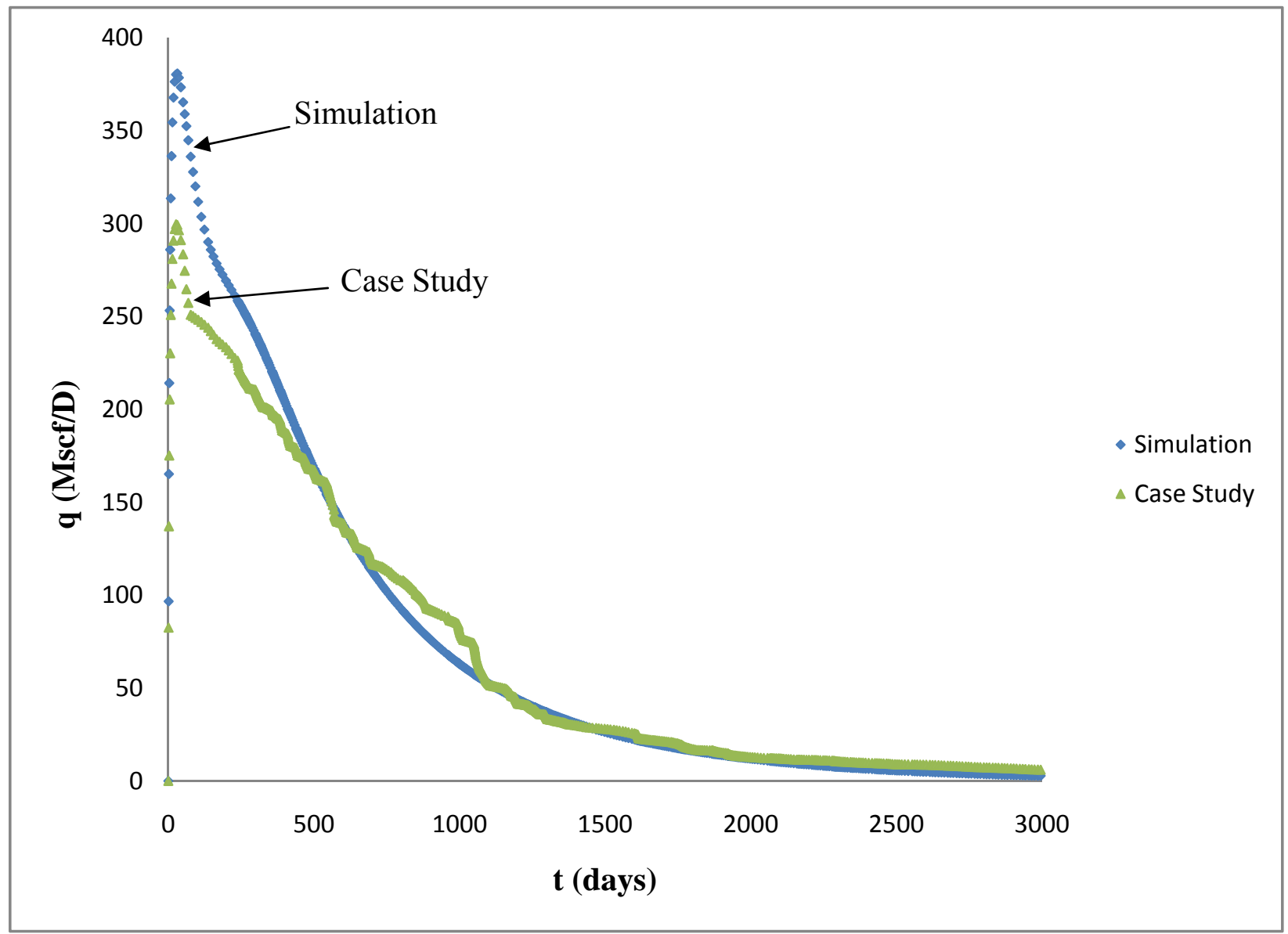

Figure 25. Comparison of the Predicted Gas Production

From the result for Figure 25, the predicted production rate from the type curves closely match production from the simulation concluding the correlation developed for $\mathrm{q}_{(\text {peakD) }}$ can provide reliable results.

The cumulative gas production should be compared for the economical evaluation because the peak gas rate is normally a short period of time and can have significant deviation. Due to the short time to reach $\mathrm{q}_{\mathrm{peak}}$ the cumulative production corrects the deviation between the gas rates for the early years of production. Figure 26 shows that the 
cumulative production is very similar for 1000 days (about 2 years) and the percent error is reduced for $21 \%$ from the peak to $3.6 \%$ on the cumulative production.

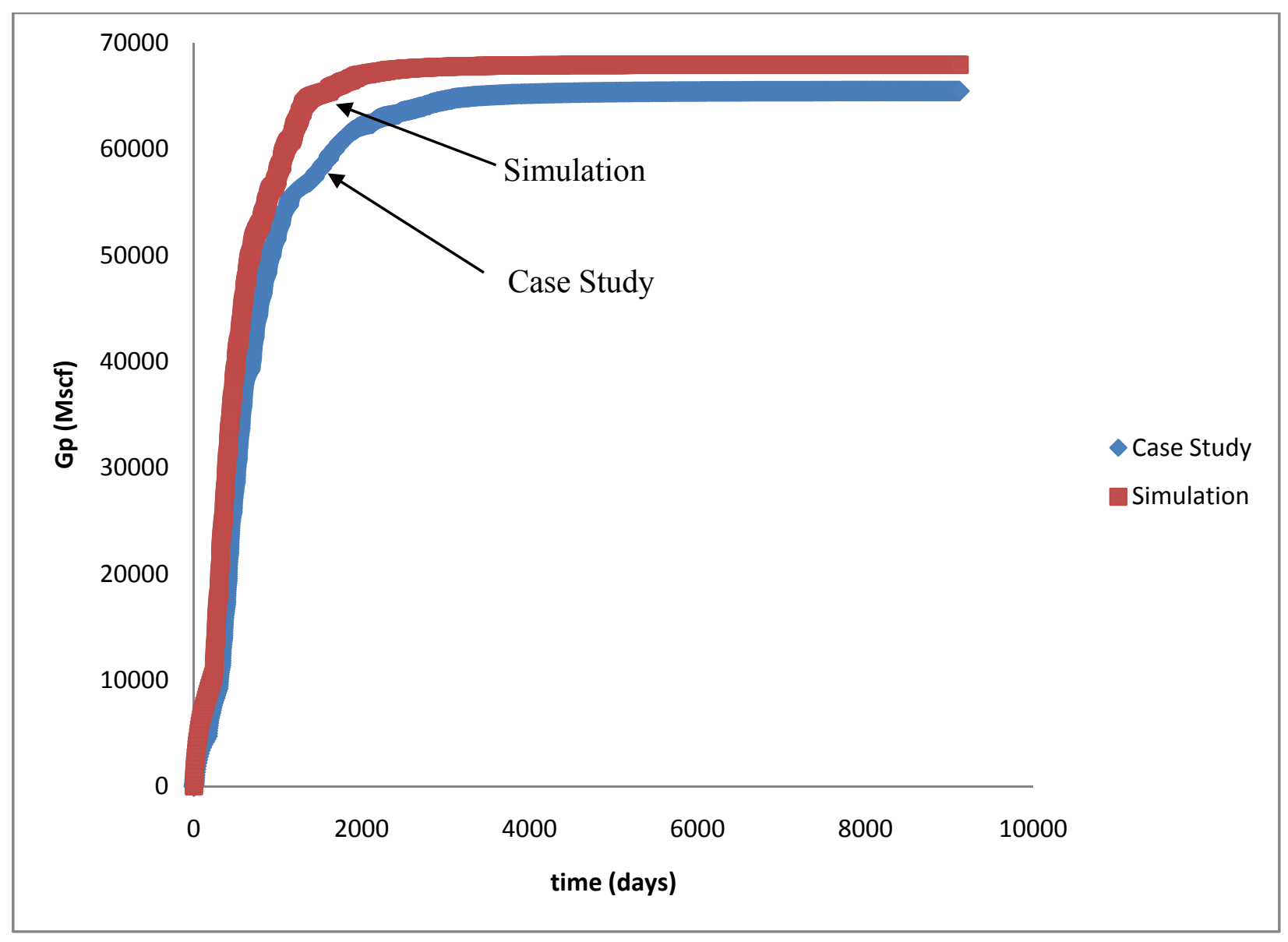

Figure 26. Comparison of Predicted Cumulative Gas Production 


\section{CONCLUSIONS AND RECOMMENDATIONS}

The main focus of this research was to develop a set of type curves that could be used by independent producers to evaluate and predict production data for unconventional horizontal wells. The research took into account reservoir parameters to determine the impacts on production. Based on the results, the following conclusions and recommendations were made:

1. The effects of porosity, Langmuir pressure and volume, permeability, and L/Ye ratio were studied to evaluate their impact on type curves. The impact of these parameters had minimal effect on the type curves.

2. Two dimensionless groups are needed for developing type curves for horizontal CBM wells.

3. Unconventional shale gas reservoirs cannot use the same type curves

4. A reliable correlation for predicting the peak gas rate for CBM was developed that allowed the type curves to be used as a tool for predicting production.

Even though CBM and shale are both unconventional reservoirs, both have absorbed gas in their respective matrix and the absorbed gas is released by lowering the reservoir pressure, there is no similarities in the type curves. Further studies need to be completed to develop more in depth and reliable type curves for horizontal unconventional shale reservoirs. This research can be helpful in the development and implications of new technology and growth for unconventional gas reservoirs. The results lead to a quick and reliable tool for estimating the gas production for independent gas producers. 


\section{NOMENCLATURE}

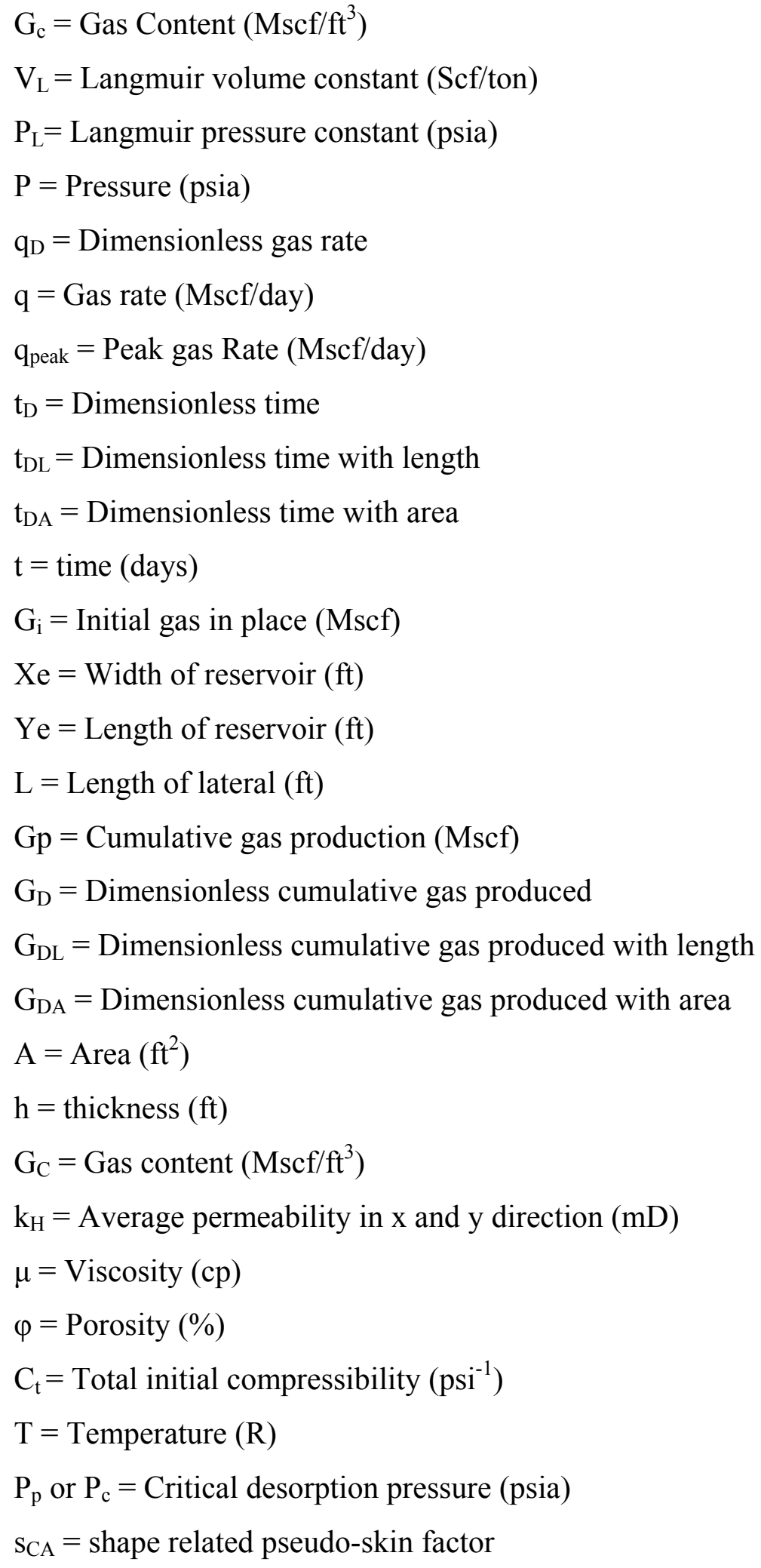


$c^{\prime}=$ shape factor conversion constant

$\mathrm{P}_{\mathrm{wf}}=$ flowing bottom hole pressure (psia)

$\mathrm{Z}=\mathrm{z}$-factor

$\mathrm{s}=$ skin factor

$r_{e}=$ drainage radius $(\mathrm{ft})$

$\mathrm{r}_{\mathrm{w}}=$ wellbore radius $(\mathrm{ft})$ 


\section{REFERENCES}

1. Annual Energy Outlook 2004 with Projections to 2025," Market Trends-Oil and Natural Gas, Energy Information Administration.

2. Byrer, C.W., Mroz, T.H., and Covatch, G.L.: "Coalbed Methane Production Potential in U.S. Basins," JPT (July 1987) 39, No. 7, 821-834.

3. Rogers, Ruby E., Muthukumarappan Ramurthy, Gary Rodvelt, and Mike Mullen.Coalbed Methane: Principles and Practices. 3rd Edition. 2007, 14.

4. McMurray, T.A.: "Tax Credit is Giving Life to Coal Gas," American Oil \& Gas Reporter (January 1989) 21-27.

5. Rogers, Ruby E., Muthukumarappan Ramurthy, Gary Rodvelt, and Mike Mullen.Coalbed Methane: Principles and Practices. 3rd Edition. 2007, 77.

6. Olszewski, A.J. and Schraufnagel, R.A.: "Development of Formation Evaluation Technology for Coalbed Methane Development," Quarterly Review of Methane from Coalseams Technology (October 1992) 10, No. 1, 27-35.

7. Rogers, Ruby E., Muthukumarappan Ramurthy, Gary Rodvelt, and Mike Mullen.Coalbed Methane: Principles and Practices. 3rd Edition. 2007, 20-21.

8. Rogers, Ruby E., Muthukumarappan Ramurthy, Gary Rodvelt, and Mike Mullen.Coalbed Methane: Principles and Practices. 3rd Edition. 2007, 22.

9. Aminian, Kashy. Lectures 6 and 10. Advanced Natural Gas Engineering. Morgantown: West Virginia University, Spring 2009.

10. Kim, A.G.: "Estimating Methane Content of Bituminous Coalbeds from Adsorptive Data,"U.S. Bureau of Mines, Report of Investigation, RI 8245.

11. McElhiney, J.E., Koenig, R.A., and Schraufnagel, R.A.: "Evaluation of CBM Reserves Involves Different Techniques," Oil \& Gas J. (October 1989) 87, No. 44, 63-72.

12. Bell, G.J., Jones, A.H., Morales, R.H., and Schraufnagel, R.A.: "Coalseam Hydraulic Fracture Propagation on a Laboratory Scale," Proc., CBM Symposium, Tuscaloosa, Alabama (April 1989) 417-425.

13. Rightmire, C.T.: "CBM Resource," CBM Resources of the United States, American Association of Petroleum Geologists Studies in Geology (1984) No. 17, 8-9. 
14. "Directional Drilling Technology." U.S. Environmental Protection Agency. 27 May $2009<$ http://www.epa.gov/coalbed/docs/dir-drilling.pdf $>$.

15. K. Aminian, S. Ameri, M. Sanchez, A. Garcia, and A. Bhavsar. "Type Curves for Coalbed Methane Production Prediction." SPE. 91482(2004).

16. Aminian, K., and S. Ameri. "Predicting Horizontal Well Production Performance Using Type Curves." SPE 19342(1989).

17. Eclipse Reservoir Engineering Software Manual. 2007. Schlumberger.

18. Joshi, S.D.. Horizontal Well Technology. Ok: PennWell, 1991. Print.

19. Mutalik, P. N., Godbole, S. P., and Joshi, S.D.: "Effect of Drainage Area Shapes on Horizontal Well Productivity," paper SPE 18301, presented in the SPE $63^{\text {rd }}$ Annual Technical Conference, Houston, Texas, Oct 2-5. 1988.

20. Gash, B. W.: "Measurement of Rock Properties in Coal for Coalbed Methane Production”, SPE 22909, SPE Annual Technical Conference and Exhibition, 1991.

21. K. Aminian, S. Ameri, Bhavsar. "Type Curves-Based Production Tool for CBM Prospects." SPE. 111194 (2007). 